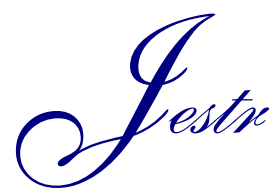

Research Article

www.jestr.org

\title{
Design of 16 Bit Vedic Multiplier Using Semi-Custom and Full Custom Approach
}

\author{
K. Nehru* and T.T.Linju
}

Institute of Aeronautical Engineering, Department of ECE, Hyderabad

Received 4 May 2016; Accepted 2 April 2017

\begin{abstract}
The Digital processor requires high speed and low power multiplier. This thesis is devoted to the design of vedic multiplier using semi-custom and full custom approach. The vedic multiplier is a specimen of interest because of its modular design where smaller blocks can be used for to design the bigger ones. Though the adders in the multiplier suffers from the carry propagation delay.So we incorporate a different kinds of adders and the performance was determined by the trade-offs between power delay and area parameters. The vedic mathematics algorithms like urdhvatiryakbhyam were used in the realization of the Vedic multiplier.The Semi-custom and Full custom approaches are utilized in designing the vedic multiplier.The Vedic multiplier was implemented in FARADAYS 180nm as well as FARADAYS $65 \mathrm{~nm}$ technology for all the design corners in the semi-custom approach.In the Full custom approach we use Tanner EDA for schematic entry and simulation.
\end{abstract}

Keywords: CSLA, low-power, urdhvatiryakbhyam, VLSI.

\section{Introduction}

Multipliers is most commonly used in most of the digital signal processing applications. But the multiplication involves lot of computations such as partial product generation and shift and addtion of partial products. The moore's law states that the no.of transistor doubles approximately every two years.As the transistor density increases the power consumption of the digital IC became a major consideration for the designers. The dynamic power disipation is influenced by the frequency of operation,switching capacitance,supply voltage and activity factor.More over there is always a trade off between the speed, power and hardware utilised. Several algorithms were proposed in order to make the multiplication effective.In this paper we propose a multiplier design using vedic mathematics algorithm Urdhva tiryakbhyam (vertical and crosswise algorithm). The vedic mathematics can simplify the computations and increases the speed of computation which in turn increases the speed. More over the vedic multiplier has modular architecture than the other multipliers [1].

But the ripple carry adders (RCA) used in the vedic multiplier suffers from propagation delay. So we replace some other adders like carry skip adder, carry look ahead adder and carry select adder and analyse the performance in terms of power,delay and area. The use of carry select adder (CSLA) may help the multiplier to work faster, but at the cost of excess hardware almost twice that of ripple carry adder. Moreover the use of multiplexers increases the area of the digital ICs. So the optimisation of carry select adder may be useful in optimising the carry select adder. The use of add one circuit instead of a ripple carry adder block with carry

*E-mail address: nnehruk@gmail.com

ISSN: 1791-2377 C 2017 Eastern Macedonia and Thrace Institute of Technology. All rights reserved. one was a good option [4]. But this design is penalised by the delay factor. So in our design we use binary to excess 1 (BEC) circuit in order to make the multiplier to consume less power.

\section{Architecture of Vedic Multiplier}

This multiplier uses the vedic mathematics algorithm urdhvatiryakbhyam (vertical and crosswise algorithm) [1].Let see the illustration of using this algorithm.

\subsection{2x2 Multiplier}

Let's take multiplication of 2 bit inputs A1A0 and B1B0.

In vedic method, $\mathrm{P} 0$ is vertical product of bit $\mathrm{A} 0$ and $\mathrm{B} 0$, $\mathrm{P} 1$ is addition of crosswise bit multiplication i.e. $\mathrm{A} 1$ \& $\mathrm{B} 0$ and $\mathrm{A} 0$ and $\mathrm{B} 1$, and $\mathrm{P} 2$ is again vertical product of bits $\mathrm{A} 1$ and B1 with the carry generated, if any, from the previous addition during $\mathrm{P} 1$. P3 output is nothing but carry generated during P2 calculation. This module is known as $2 \times 2$ multiplier block.
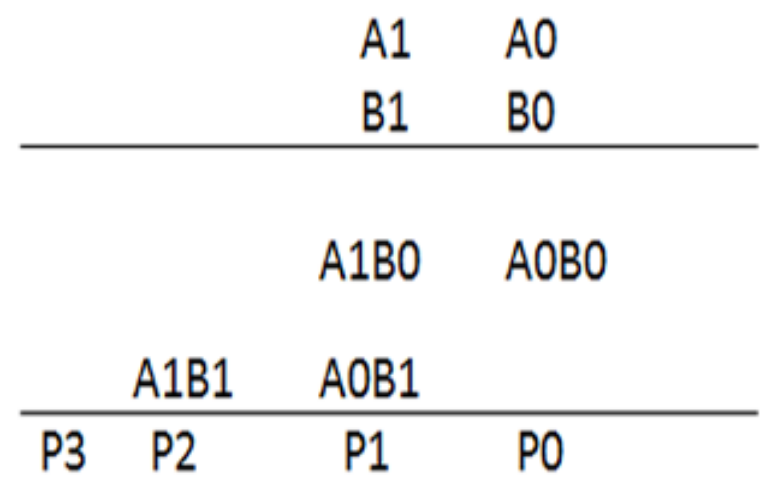

Fig. 1. 2x2 Multiplication algorithm 


\section{2. $4 \times 4$ Multiplication}

For multiplication of higher order bits, little modification is required. Let $\mathrm{A} 3 \mathrm{~A} 2 \mathrm{~A} 1 \mathrm{~A} 0$ and $\mathrm{B} 3 \mathrm{~B} 2 \mathrm{~B} 1 \mathrm{~B} 0$, the output for the multiplication results in P7P6P5P4P3P2P1P0. Block diagram of $4 \times 4$ vedic multiplier is given in Fig.2.

$$
\begin{gathered}
\mathrm{A}_{3} \mathrm{~A}_{2} \quad \mathrm{~A}_{1} \mathrm{~A}_{0} \\
\mathrm{X} \mathrm{B}_{3} \mathrm{~B}_{2} \quad \mathrm{~B}_{1} \mathrm{~B}_{0}
\end{gathered}
$$

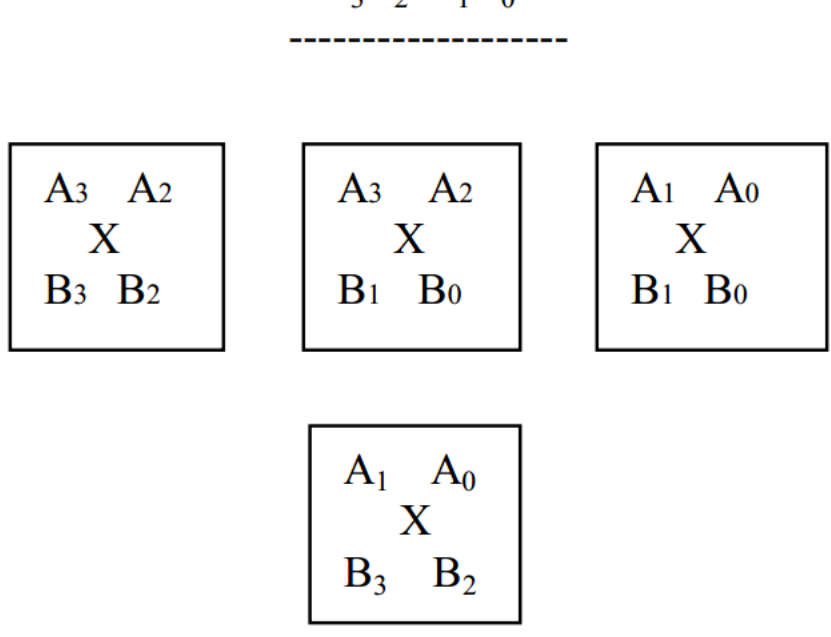

Fig. 2. 4x4 Multiplier block diagram

Each of the blocks denoted as square boxes in the above figure are $2 \times 2$ multipliers. On applying the algorithm the least bits $\mathrm{A} 1 \mathrm{~A} 0$ and $\mathrm{B} 1 \mathrm{~B} 0$ forms the first block, and the crosswise multiplication of the least bits and most bits $\mathrm{A} 3 \mathrm{~A} 2$ with $\mathrm{B} 1 \mathrm{~B} 0$ and $\mathrm{A} 1 \mathrm{~A} 0$ with $\mathrm{B} 3 \mathrm{~B} 2$ forms the second and third blocks and the vertical multiplication of the most bits $\mathrm{A} 3 \mathrm{~A} 2$ and $\mathrm{B} 3 \mathrm{~B} 2$. The results of these blocks is given as

$$
\begin{array}{llll}
\mathrm{A}_{3} \mathrm{~A}_{2} & \mathrm{~A}_{3} \mathrm{~A}_{2} & \mathrm{~A}_{1} \mathrm{~A}_{0} & \mathrm{~A}_{1} \mathrm{~A}_{0} \\
\mathrm{~B}_{3} \mathrm{~B}_{2} & \mathrm{~B}_{1} \mathrm{~B}_{0} & \mathrm{~B}_{3} \mathrm{~B}_{2} & \mathrm{~B}_{1} \mathrm{~B}_{0} \\
-------- & ---\mathrm{S} \\
\hdashline \mathrm{S}_{33} \mathrm{~S}_{32} \mathrm{~S}_{31} \mathrm{~S}_{30} & \mathrm{~S}_{23} \mathrm{~S}_{22} \mathrm{~S}_{21} \mathrm{~S}_{20} & \mathrm{~S}_{13} \mathrm{~S}_{12} \mathrm{~S}_{11} \mathrm{~S}_{10} & \mathrm{~S}_{03} \mathrm{~S}_{02} \mathrm{~S}_{01} \mathrm{~S}_{00}
\end{array}
$$

The result is obtained by adding S13S12S11S10 with S23S22S21S20. Now this sum is added with Most Significant two bits of first block andLeast Significant two bits of fourth block like S31S30S03S02.

$$
\begin{aligned}
& \begin{array}{cccccc} 
& 0 & 0 & S_{03} & S_{02} & \\
S_{33} S_{32} & S_{23} & S_{22} & S_{21} & S_{20} & \\
& S_{13} & S_{12} & S_{11} & S_{10} & \\
& S_{31} & S_{30} & 0 & 0 & \\
& & & & & \\
\hline
\end{array} \\
& \begin{array}{llllll}
P_{7} P_{6} & P_{5} & P_{4} & P_{3} & P_{2} & P_{1} P_{0}
\end{array}
\end{aligned}
$$

\subsection{8x8 Multiplication}

For 8 bit multiplicand A is splitted into pair of four bits AHAL. Similarly multiplier B can be decomposed into BH-BL. The urdhavatiryakbhyam algorithm is applied. The outputs of 4X 4 bit multipliers are added accordingly to obtain the final product. Thus, we require two adders in order to perform the multiplication. The basic building block of $8 \times 8$ bits Vedic multiplier is $4 \times 4$ bits multiplier. For $8 \times 8$ bits multiplier the $4 \times 4$ bits multiplier units has been used as basic components and for $4 \times 4$ bit vedic multiplier the basic block is $2 \times 2$ multiplier. Thus it forms a modular architecture. The sample calculation is given below

\begin{tabular}{llll} 
For example & & & \\
& 1111 & 1111 & \\
& 0000 & 1001 & \\
\hline 0000 & 0000 & 0000 & 0111 \\
& 1000 & 0111 & \\
& 0000 & 1000 & \\
\hline 0000 & 1000 & 1111 & 0111 \\
& &
\end{tabular}

Fig. 3. Sample Calculation of $8 \times 8$ multiplication

\section{Architecture of Existing 16 Bit Vedic Multiplier}

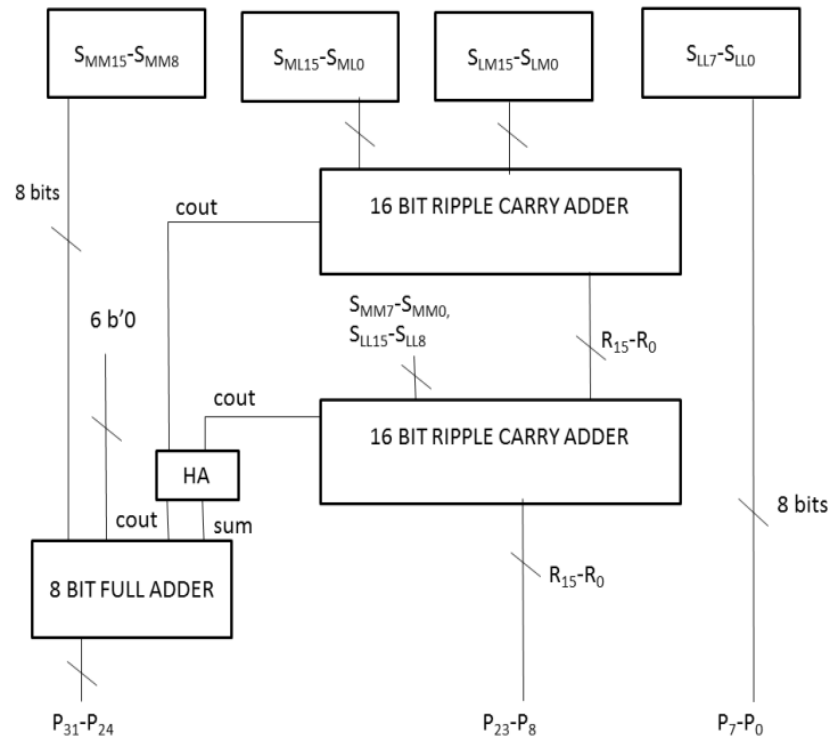

Fig. 4. Architecture of Vedic multiplier

The $16 \times 16$ bit multiplier is built using $8 \times 8$ bit blocks. The 16 bit multiplicand A can is divided into pair of 8 bits AH-AL. Similarly multiplier B is divided into BH-BL. The outputs of $8 \times 8$ bit multipliers are added accordingly to obtain the 32 bits final product. Two 16 bit ripple carry adders are used for the addition of partial products. The ripple carry adder is simplest form among adder families. The least hardware requirements and less power consumption make the adder attractive for low power applications. The problem in using the ripple carry adders are they suffer from carry propagation delay. The carry will be available only after passing through all the full adder blocks. We cannot entertain such delay in communication systems where high speed digital signal processing is required. 


\section{Proposed Vedic Multipliers}

In the existing $16 \times 16$ multiplier architecture the generation of the partial outputs from the low order multipliers occurs concurrently.But the large ripple carry adders will contribute to larger delays as the size of the multiplier increases.So, several architectures are proposed by replacing the 16 bit RCA with some other adders and analyse their performance with power, delay and area attributes.

\subsection{Vedic Multiplier Using Carry Skip Adder}

In the existing multiplier, the ripple carry adder block is replaced by the carry skip adder.

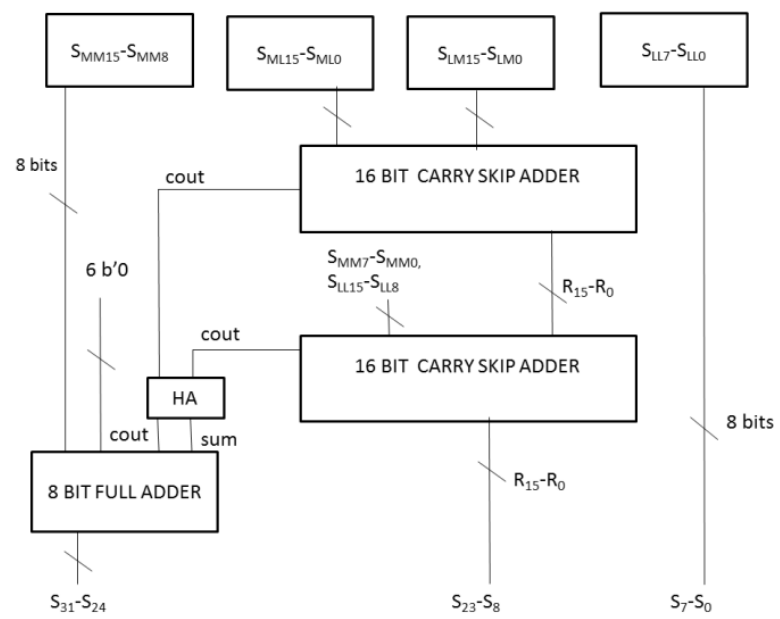

Fig. 5. Vedic Multiplier using Carry skip adder

The two bit streams to be added are divided into blocks of equal length say 16 bits are divided into two eight bit streams. The carry is skipped through the stages based on un-equivalence condition. This is done by Exclusive OR ing each individual block which leads to comparison string which is subjected to AND operation within itself. If for each cell in the block $\mathrm{Ai} \neq \mathrm{Bi}$ then we say that a carry can skip over the block otherwise if $\mathrm{Ai}=\mathrm{Bi}$ we shall say that the carry must be generated in the block. This operation is accomplised by the use of multiplexers.

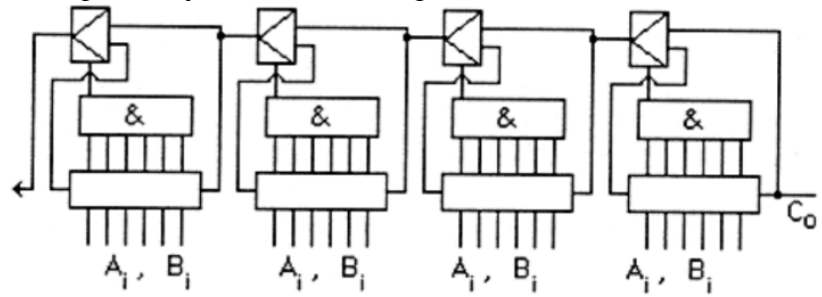

$$
\prod_{A_{i}, B_{i} i=0,1, \ldots}^{\uparrow} \text { computes }\left(A_{0} \oplus B_{0}\right) \cdot\left(A_{1} \oplus B_{1}\right) \ldots\left(A_{5} \oplus B_{5}\right)
$$

Fig. 6. Carry Skip Adder

\subsection{Vedic Multiplier using Carry Look Ahead Adder} In the existing multiplier,the RCA block is replaced by the carry look ahead adder.

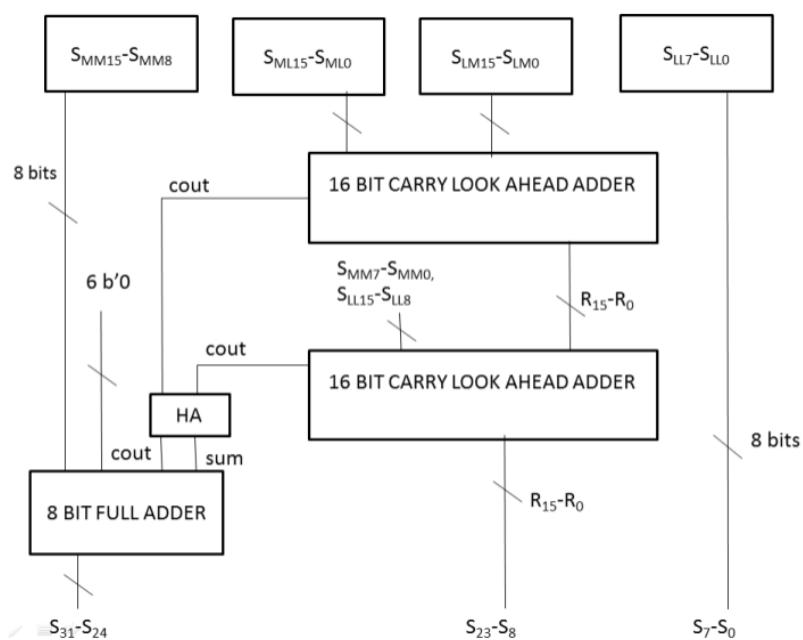

Fig. 7. Vedic multiplier using Carry Look Ahead adder

Carry look aheadadder produces carry bit faster due to carry bits generated in parallel by an additional circuit.This technique uses carry bypass logic chain which has generate and propagate functions to speed up the carry propagation. The expressions for carry generation are

Propagate function, $p_{i}=a_{i}+b_{i}$

Generate function, $g_{i}=a_{i} b_{i}$

Sum si $=\mathrm{p}_{\mathrm{i}}^{\wedge} \mathrm{c}_{\mathrm{i}}$

Carry $\mathrm{c}_{\mathrm{i}+1}=\mathrm{g}_{\mathrm{i}}+\mathrm{p}_{\mathrm{i}} \mathrm{c}_{\mathrm{i}}$

But the additional circuitry is achieved at the cost of extra hardware and power.Moreover, when the no.of bits increases the complexity of implemeting the carry look ahead adder is cumbersome. So it is not perferable to use conventional carry look ahead adder, rather we could break the circuit into small blocks and low order adders can be used.

\subsection{Vedic Multiplier using Carry Select Adder}

In the existing multiplier, the RCA block is replaced by the carry select adder.

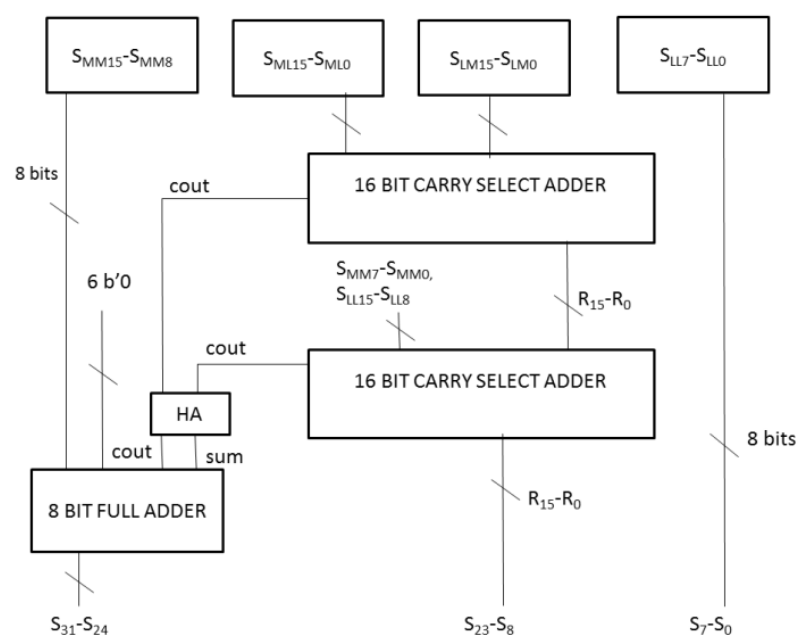

Fig. 8. Vedic multiplier using Carry select adder 
The concept of the carry-select adder is to compute alternative results in parallel and subsequently selecting the correct result with single or multiple stages. In carry-select adders both sum and carry bits are calculated for the two alternatives: carry " 0 " and " 1 ". Once the carry-in is fired, the correct computation is chosen using multiplexers to produce the desired output.Therefore instead of waiting for the carry-in to calculate the sum, the sum is correctly output as soon as the carry-in gets there. The time taken to compute the sum is then avoided which results in a good improvement in speed.

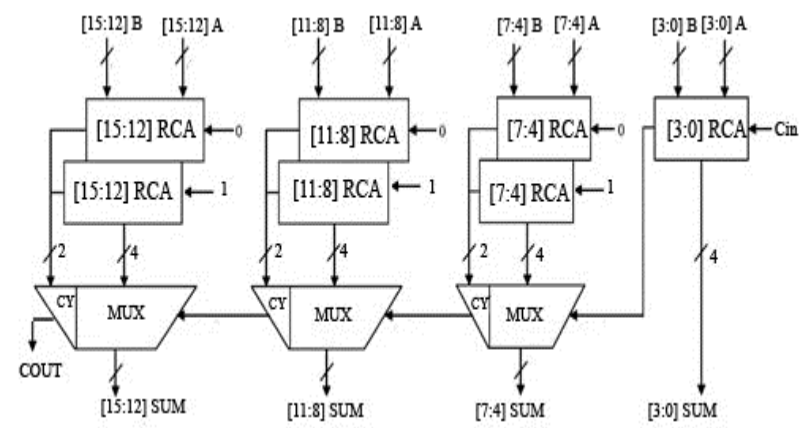

Fig. 9. Carry Select adder

The use of carry select adder increases the hardware thereby more power consumtion which is twice that of rippe carry adder.The use of multiplexer increases the chip area.But consierable increase in the speed is achieved. So, optimisation of the carry select adder can be useful in increasing the speed of the mutiplier speed.

\subsection{Vedic Multiplier using Modified Carry Select Adder with BEC}

In the existing multiplier, the RCA block is replaced by the modified carry select adder with BEC (Binary to Excess-1).

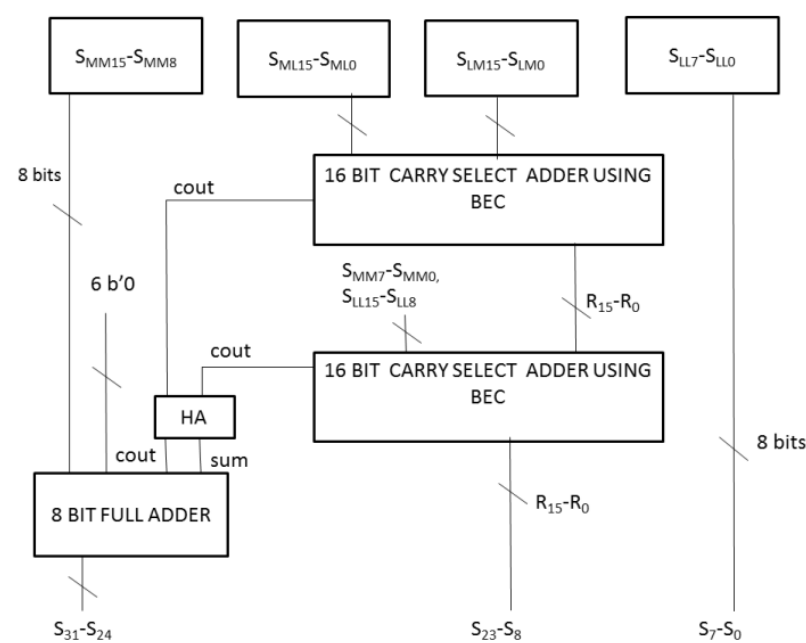

Fig. 10. Vedic Multiplier using Carry Select adder with BEC

In the carry select adder the there are two stages of ripple carry adder with carry 0 and carry 1 , once the carry is delivered from the previous stage, then the output is selected based on the input carry. Comparing the results from the ripple carrystages with $c_{i n} 0$ andc $c_{\text {in }} 1$. The outputs of the ripple carry stage with $c_{\text {in }}$ value 1 will be one excess than that of the ripple carry stage with $\mathrm{c}_{\mathrm{in}}$ value 0 . So, there is an option of Binary to Excess - 1 (BEC-1) instead of the ripple carry block with $\mathrm{c}_{\mathrm{in}} 1$. The function table of the 4 bit BEC is given in Table1.

Table 1.BEC Truth Table

\begin{tabular}{l|l}
\hline Binary (B) & BEC-1 (X) \\
\hline 0000 & 0001 \\
0001 & 0010 \\
0010 & 0011 \\
$\ldots$ & $\ldots$ \\
1110 & 1111 \\
1111 & xxxx \\
\hline
\end{tabular}

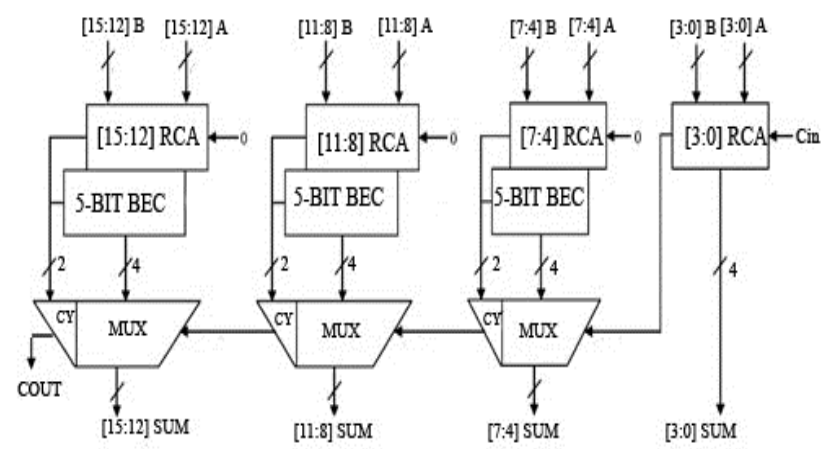

Fig. 11. Modified Carry Select adder

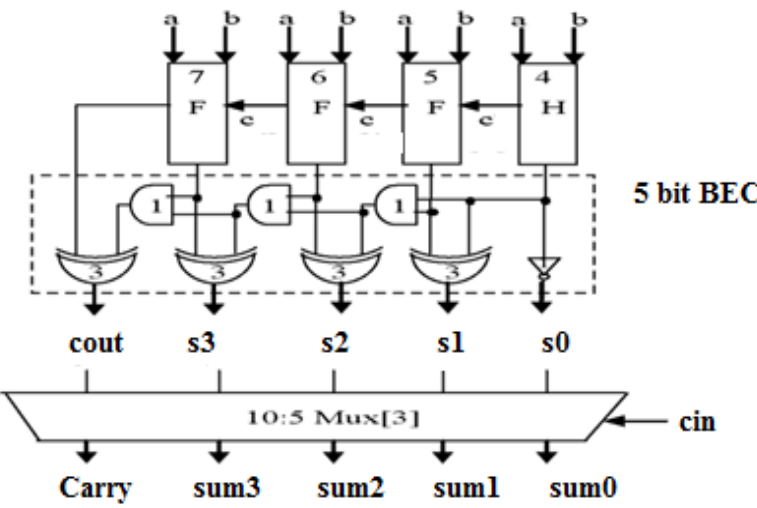

Fig. 12. 5-bit Binary to Excess 1 block

5.4. Vedic Multiplier using SQRT Carry Select adder In the existing Multiplier, the RCA block is replaced by the square root carry select adder (SQRT CSLA) a variant of carry select adder.

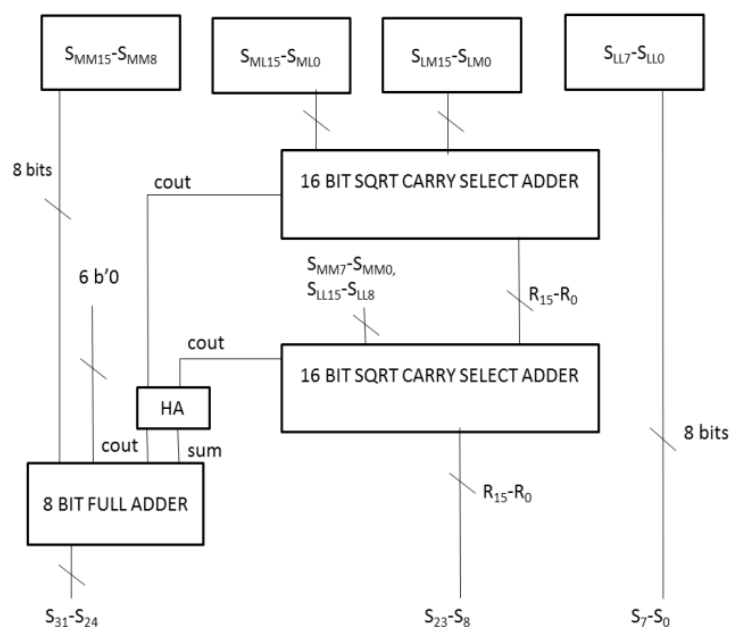

Fig. 13. Vedic multiplier using SQRT Carry select adder 
The square root carry select adder is a variant of the conventional carry select adder where it has a balanced delay than the CSLA. The SQRT CSLA differs from the CSLA in a way that the RCA blocks are of different sizes. The smaller blocks were placed first and the size increases as towards the higher order bits.

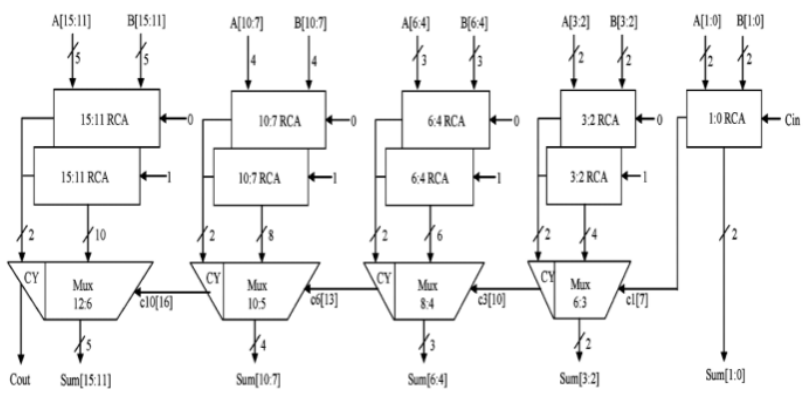

Fig. 14. SQRT Carry Select adder

5.6. Vedic Multiplier using SQRT Carry Select Adder with BEC

In the existing multiplier, the RCA block is replaced by the modified square root carry select adder using BEC.

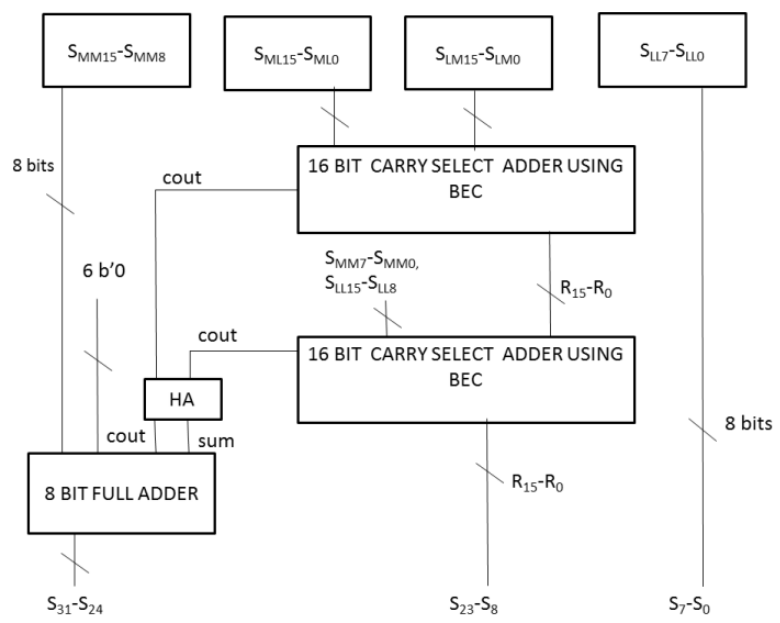

Fig. 15. Vedic Multiplier using SQRT Carry Select adder with BEC

In the square root carry select adder the variable sizes of parallel RCA blocks with $\operatorname{cin}=$ ' 0 ' and $\operatorname{cin}=$ ' 1 ' are used. In modified SQRT CSLA, the RCA block with cin $=$ ' 1 ' block is replaced by corresponding BEC group. The 2 bit,3bit,4bit, 5 bit RCA blocks with $\operatorname{cin}=1$ are replaced with 3 bit,4bit, 5bit,6bit BEC blocks respectively.

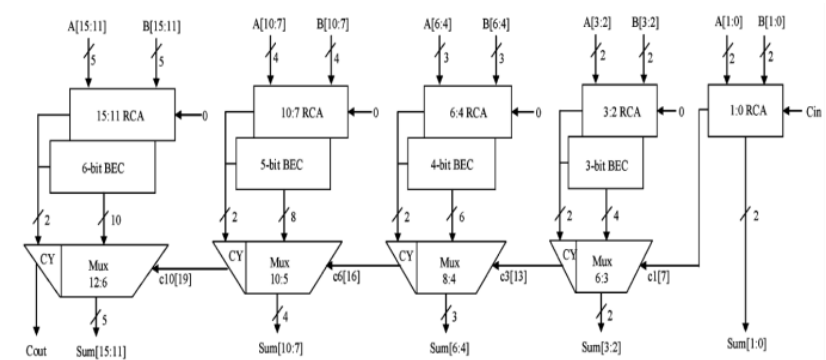

Fig. 16. Modified SQRT Carry Select adder with BEC
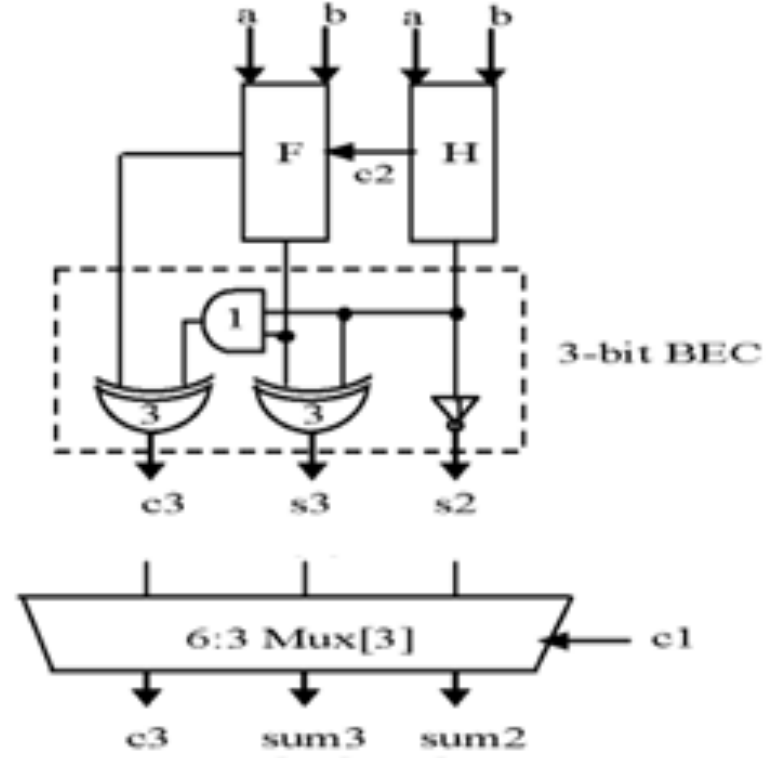

Fig. 17. 3-bit BEC
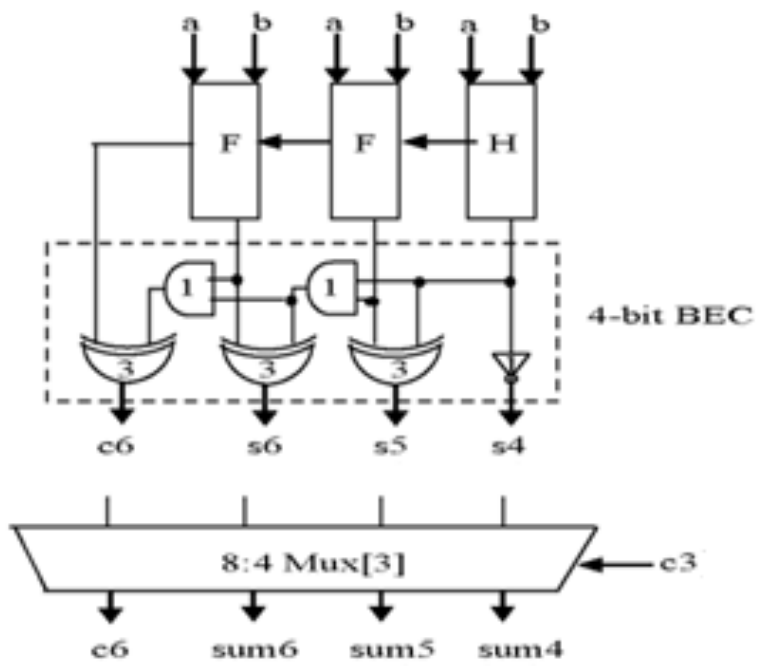

Fig. 18. 4-bit BEC
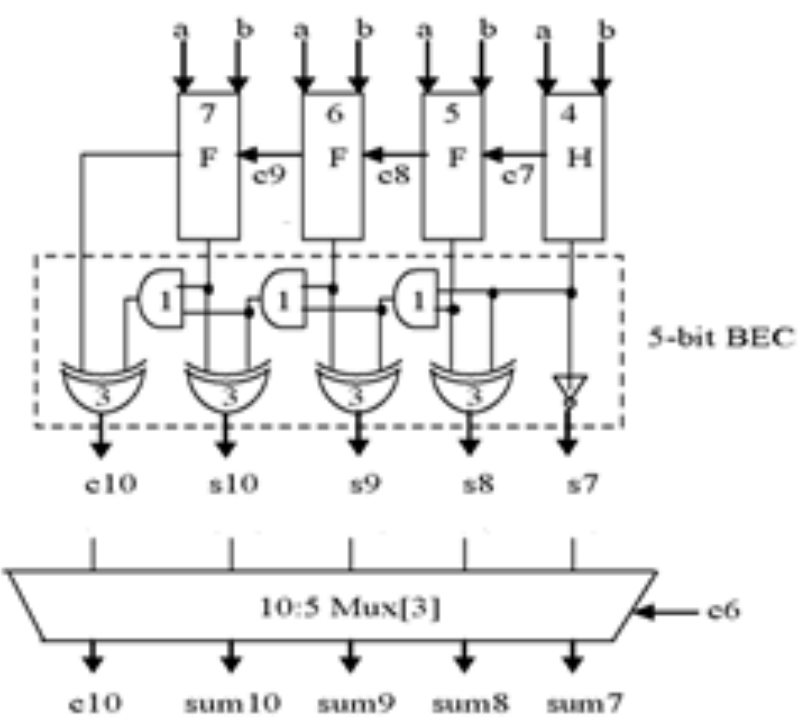

Fig. 19. 5-bit BEC 


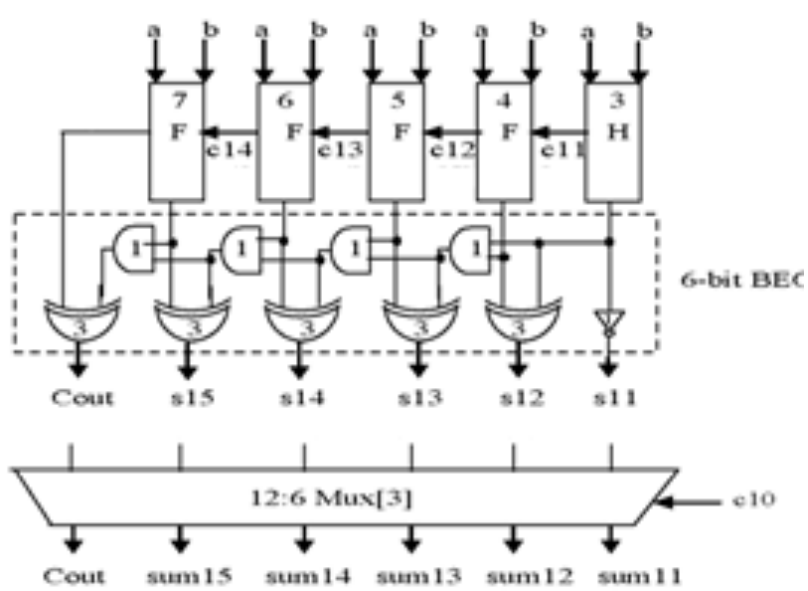

Fig. 20. 6-bit BEC

\section{Implementation}

For the implementation we took both semi-custom and full custom approaches. For the semi-custom approach the synopsis design compiler was used for synthesis and cadence SoCencounter was used for layout design.All the existing multipliers and designed using verilog HDL using dataflow and behavioural modelling. The multipliers were implemented in both Faradays $180 \mathrm{~nm}$ as well as $65 \mathrm{~nm}$ technology for all the process corners. For full custom approach we use tanner EDA S-edit for schematic entry and T-SPICE for circuit simulation.

\section{Results and Discussion}

Table 2.Results of Fast-Fast design corner (Faradays $180 \mathrm{~nm})$

\begin{tabular}{|c|c|c|c|c|}
\hline \multicolumn{5}{|c|}{ SLOW-SLOW DESIGN CORNER } \\
\hline & $\begin{array}{c}\text { POWER } \\
\mathrm{mW}\end{array}$ & $\begin{array}{c}\text { DELAY } \\
n S\end{array}$ & $\begin{array}{c}\text { AREA } \\
\mu \mathrm{m}^{2}\end{array}$ & $\begin{array}{c}\text { POWER } \\
\text { DELAY } \\
\text { PRODUC } \\
\text { T } \\
\left(10^{-12}\right)\end{array}$ \\
\hline $\begin{array}{l}\text { MUL_RC } \\
\text { A }\end{array}$ & 3.2173 & 2.23 & 10448.37 & 7.174579 \\
\hline $\begin{array}{l}\text { MUL_CL } \\
\text { A }\end{array}$ & 3.2225 & 2.21 & 10435.82 & 7.121575 \\
\hline $\begin{array}{l}\text { MUL_CS } \\
\text { KA }\end{array}$ & 3.2819 & 2.45 & 10518.93 & 8.040655 \\
\hline $\begin{array}{l}\text { MUL_CSL } \\
\text { A }\end{array}$ & 5.4879 & 2.2 & 13077.12 & 12.07338 \\
\hline $\begin{array}{l}\text { MUL_CSL } \\
\text { A_BEC }\end{array}$ & 4.5106 & 2.22 & 12098.69 & 10.01353 \\
\hline $\begin{array}{l}\text { MŨL_SQ } \\
\text { RTCSLA }\end{array}$ & 4.1358 & 2.16 & 11334.29 & 8.933328 \\
\hline $\begin{array}{l}\text { MUL_SQ } \\
\text { RTCSLA_ } \\
\text { BEC }\end{array}$ & 3.8093 & 2.17 & 11003.44 & 8.266181 \\
\hline
\end{tabular}

In the above table, The results of all the multiplier designs using faradays $180 \mathrm{~nm}$ technology Fast- Fast design corner is tabulated. As far as power is concerned the multiplier with ripple carry adder is the best option but it has considerable amount of delay than all the other designs. The delay in carry select adder was good but it has very high power consumption. But the multiplier designed with modified carry select adder using BEC has the less power consumption than the multiplier with carry select adder but it has a bit more delay. The variant multiplier using square root carry select adder has less power and delay than the carry select adder. But the modified square root carry select adder looks promising as it has less delay and the power consumption was also bit more than the ripple carry adder.

Table 3. Results of Slow-Slow design corner (Faradays $180 \mathrm{~nm})$

\begin{tabular}{|c|c|c|c|c|}
\hline \multicolumn{5}{|c|}{ SLOW-SLOW DESIGN CORNER } \\
\hline & $\begin{array}{c}\text { POWER } \\
\text { mW }\end{array}$ & $\begin{array}{c}\text { DELAY } \\
\text { nS }\end{array}$ & $\begin{array}{c}\text { AREA } \\
\mu^{2}\end{array}$ & $\begin{array}{c}\text { POWER } \\
\text { DELAY } \\
\text { PRODUC } \\
T \\
\left(10^{-12}\right) \\
\end{array}$ \\
\hline MUL_RCA & 1.9989 & 6.3 & 10448.37 & 12.59307 \\
\hline MUL_CLA & 2.0039 & 6.28 & 10435.82 & 12.58449 \\
\hline MUL_CSKA & 2.0378 & 6.95 & 10518.93 & 14.16271 \\
\hline MUL_CSLA & 3.3408 & 6.22 & 13077.12 & 20.77978 \\
\hline $\begin{array}{l}\text { MUL_CSLA_BE } \\
\mathrm{C}\end{array}$ & 2.7594 & 6.34 & 12098.69 & 17.4946 \\
\hline $\begin{array}{l}\text { MUL_SQRTCSL } \\
\text { A }\end{array}$ & 2.5342 & 6.12 & 11334.29 & 15.5093 \\
\hline $\begin{array}{l}\text { MUL_SQRTCSL } \\
\text { A_BEC }\end{array}$ & 2.3443 & 6.18 & 11003.44 & 14.48777 \\
\hline
\end{tabular}

In the above table, the results of all the multiplier designs using faradays $180 \mathrm{~nm}$ technology Slow - Slow design corner is tabulated. The Slow - Slow design corner has less power than the Fast - Fast design corner designs but the delay hikes up to greater extent.Analysing the results the multiplier with ripple carry adder has less hardware components it has the least power but the delay is pretty high. Though the multiplier with carry select adder speeds up the multiplication it consumed more power. The proposed multiplier with modified carry select adder using BEC consumes less power than the multiplier with CSLA its delay is more than the multiplier with CSLA. The multiplier with SQRT CSLA is good with least delay to all the designs. The multiplier with modified SQRT CSLA is good with power less than multiplier with SQRT CSLA adder with multiplier with SQRT CSLA and few hundred micro watts more than the multiplier RCA adder.

Table 4. Comparisons of Typical-Typical design corner (Faradays 180nm)

\begin{tabular}{c|c|c|c|c}
\hline \multicolumn{5}{c}{ TYPICAL-TYPICAL DESIGN CORNER } \\
\hline & $\begin{array}{c}\text { POWER } \\
\mathrm{mW}\end{array}$ & $\begin{array}{c}\text { DELAY } \\
\mathrm{nS}\end{array}$ & $\begin{array}{c}\text { AREA } \\
\mu \mathrm{m}^{2}\end{array}$ & $\begin{array}{c}\text { POWER } \\
\text { DELAY } \\
\text { PRODUCT } \\
\left(10^{-12}\right)\end{array}$ \\
\hline MUL_RCA & 1.0508 & 2.84 & 4169.28 & 2.984272 \\
MUL_CSKA & 1.0324 & 2.87 & 4118.08 & 2.983636 \\
MUL_CSLA & 1.0752 & 3.22 & 4196.8 & 3.462144 \\
MUL_CSLA BEC & 1.7344 & 2.7 & 5247.07 & 4.68288 \\
MUL_SQRTCSLA & 1.443 & 2.91 & 4809.6 & 4.19913 \\
MUL_SQRTCSLA & 1.345 & 2.72 & 4532.8 & 3.6584 \\
BEC & & & & \\
MUL_RCA & 1.231 & 2.85 & 4385.6 & 3.50835 \\
\hline
\end{tabular}

In the above table, the results of all the multiplier designs using faradays $180 \mathrm{~nm}$ technology Typical-Typical design corner is tabulated. The Typical-Typical corner intermediate between the Fast-Fast and Slow - Slow cornershavingdelayandpower in consideration. The trade-offs between the designs was same as the other design corners. Here also multiplier with multiplier with SQRT CSLA using BEC holds good trade-offs between power and delay.As far as area is concerned the area for the designs is same for all the design corners. The multiplier with carry select adder has more area because of its increased hardware and multiplier with ripple carry adder has least area. 
Table 5. Comparisons of Fast-Fast design corner (Faradays $65 \mathrm{~nm})$

\begin{tabular}{|c|c|c|c|c|}
\hline \multicolumn{5}{|c|}{ FAST-FAST DESIGN CORNER } \\
\hline & $\begin{array}{c}\text { POWE } \\
\text { R } \\
\text { mW }\end{array}$ & $\begin{array}{c}\text { DELA } \\
\mathrm{Y} \\
\mathrm{nS}\end{array}$ & $\begin{array}{c}\text { AREA } \\
\mu \mathrm{m}^{2}\end{array}$ & $\begin{array}{c}\text { POWER } \\
\text { DELAY } \\
\text { PRODUC } \\
\text { T } \\
\left(10^{-12}\right)\end{array}$ \\
\hline MUL_RCA & 1.4288 & 1.77 & $\begin{array}{l}4169.2 \\
8\end{array}$ & 2.528976 \\
\hline MUL_CLA & 1.4018 & 1.79 & $\begin{array}{l}4118.0 \\
8\end{array}$ & 2.509222 \\
\hline MUL_CSKA & 1.4605 & 2.01 & 4196.8 & 2.935605 \\
\hline MUL_CSLA & 2.3511 & 1.66 & $\begin{array}{l}5247.0 \\
7\end{array}$ & 3.90282 \\
\hline MUL_CSLA_BEC & 1.9549 & 1.79 & 4809.6 & 3.49927 \\
\hline MUL SQRTC̄SLA & 1.8274 & 1.7 & 4532.8 & 3.10658 \\
\hline $\begin{array}{l}\text { MUL_SQRTCSLA_BE } \\
\mathrm{C}\end{array}$ & 1.6703 & 1.76 & 4385.6 & 2.93972 \\
\hline
\end{tabular}

In the above table, the results of all the multiplier designs using faradays $65 \mathrm{~nm}$ technology Fast- Fast design corner is tabulated. Considering the power is concerned the multiplier with ripple carry adder is the best option but it has considerable amount of delay than all the other designs. The delay in carry select adder was good but it has very high power consumption. But the multiplier designed with modified carry select adder using BEC has the less power consumption than the multiplier with carry select adder but it has a bit more delay. The variant multiplier using square root carry select adder has less power and delay than the carry select adder. But the delay in modified Square root carry select adder with BEC (1.76nS) has delay almost equal to ripple carry adder( $1.77 \mathrm{nS})$ but consumes more power than the ripple carry adder. So cannot afford such high hardware and power when a design with less hardware and power can offer the same performance.

Table 6. Comparisons of Slow-Slow design corner (Faradays 65nm)

\begin{tabular}{l|l|l|l|l}
\hline SLOW-SLOW DESIGN CORNER \\
\hline & $\begin{array}{c}\text { POWER } \\
\mathrm{mW}\end{array}$ & $\begin{array}{c}\text { DELAY } \\
\mathrm{nS}\end{array}$ & $\begin{array}{c}\text { AREA } \\
\mu \mathrm{m}^{2}\end{array}$ & $\begin{array}{c}\text { POWER } \\
\text { DELAY } \\
\text { PRODUC } \\
\mathrm{T} \\
\left(10^{-12}\right)\end{array}$ \\
\hline MUL_RCA & 0.8231 & 4.97 & 4169.28 & 4.090807 \\
MUL_CLA & 0.8097 & 5.12 & 4118.08 & 4.145664 \\
MUL_CSKA & 0.8421 & 5.65 & 4196.8 & 4.757865 \\
MUL_CSLA & 1.3491 & 4.86 & 5247.04 & 6.55662 \\
MUL_CSLA_B & 1.1257 & 5.25 & 4809.6 & 5.90992 \\
EC & & & 4532.8 & 5.04136 \\
MUL_SQRTC & 1.0481 & 4.81 & 4385.6 & 4.87632 \\
SLA & & & & \\
MUL_SQRTC & 0.9618 & 5.07 & & \\
SLA_BEC & & \multicolumn{4}{l}{} \\
\hline
\end{tabular}

In the above table the results of all the multiplier designs are tabulated. The multiplier with ripple carry adder has least power delay product and looks very good best. Though the multiplier with carry select adder has least delay but power peaks up very high. The multiplier with modified carry select adder consumes less power than multiplier with carry select adder its delay is comparatively very high. The multiplier with modified SQRT CSLA has less delay than other carry select adders it has nominal increase in power than the ripple carry adder and so this design does hold good. But the multiplier with modified SQRT CSLA with
BEC is considerable high in delay and power than multiplier with ripple carry adder it is not preferable for the slow-slow design corner of Faradays $65 \mathrm{~nm}$ technology.

Table7. Comparisons of Typical-Typical design corner ( Faradays65 nm)

\begin{tabular}{l|l|l|l|l}
\hline TYPICAL-TYPICAL DESIGN CORNER \\
\hline & $\begin{array}{c}\text { POWER } \\
\mathrm{mW}\end{array}$ & $\begin{array}{c}\text { DELAY } \\
\mathrm{nS}\end{array}$ & $\begin{array}{c}\text { AREA } \\
\mu \mathrm{m}^{2}\end{array}$ & $\begin{array}{c}\text { POWER } \\
\text { DELAY } \\
\text { PRODUC } \\
\mathrm{T}\end{array}$ \\
\hline MUL_RCA & 1.0508 & 2.84 & 4169.28 & 2.984272 \\
MUL_CSKA & 1.0324 & 2.87 & 4118.08 & 2.983636 \\
MUL_CSLA & 1.0752 & 3.22 & 4196.8 & 3.462144 \\
MUL_CSLA & 1.7344 & 2.7 & 5247.07 & 4.68288 \\
BEC & & 2.91 & 4809.6 & 4.19913 \\
MUL_SQRTC & 1.443 & 2.912 & \\
SLA & 1.345 & 2.72 & 4532.8 & 3.6584 \\
MUL_SQRTC & & 2.85 & 4385.6 & 3.50835 \\
SLA BEC & 1.231 & 2.85 \\
MUL_RCA & & \multicolumn{4}{l}{} \\
\hline
\end{tabular}

On analysing the multiplier designs implemented in faradays $65 \mathrm{~nm}$ technology typical-typical process corners. The multiplier with RCA is less power consuming and promising in delay when compared to other designs. But multiplier with carry look ahead adder also has good figures in terms of power and delay less than multiplier with RCA. Though multiplier with CSLA reduces the delay the power consumed is very high. The multiplier with CSLA BEC reduces the power than multiplier with CSLA but increases delay more than the multiplier with RCA. The multiplier with SQRT CSLA is also a good option when compared to power but the delay is almost equal to multiplier with RCA.

\section{POWER REPORT}

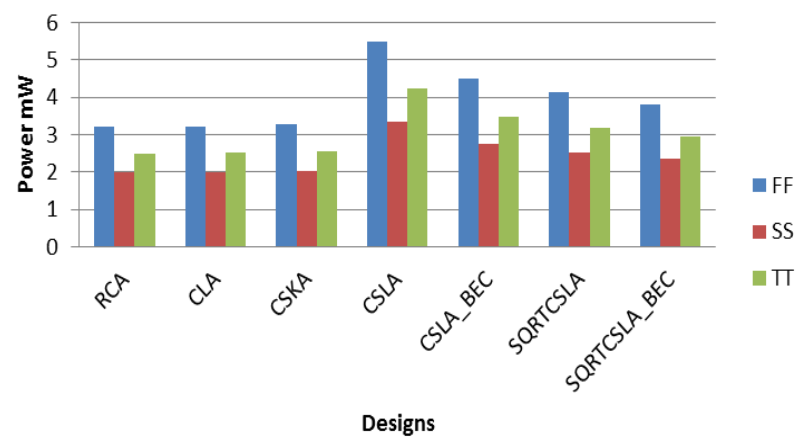

Fig. 21. Power Report (Faradays $180 \mathrm{~nm}$ )

\section{TIMING REPORT (FAST-FAST)}

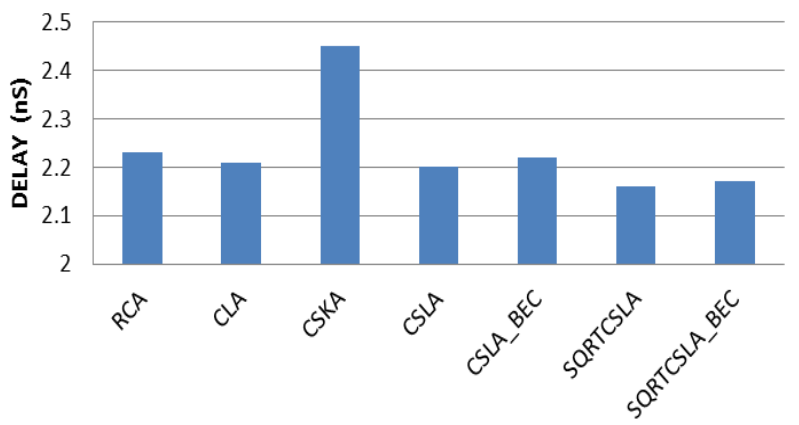

Fig. 22. Delay for Fast Fast design corner(Faradays 180 nm) 
TIMING REPORT (SLOW-SLOW)

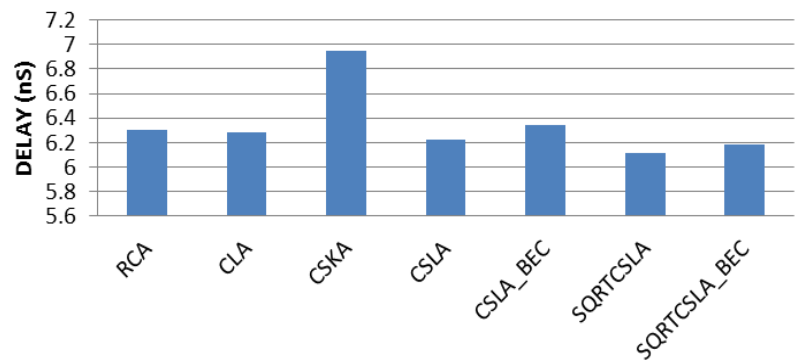

Fig. 23. DelayforSlow Slow design corner (Faradays $180 \mathrm{~nm}$ )

TIMING REPORT (TYPICAL-TYPICAL)

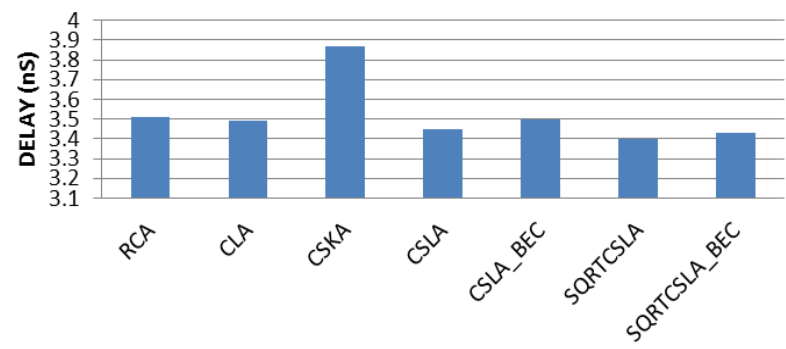

Fig. 24. Delay for TT design corner (Faradays $180 \mathrm{~nm}$ )

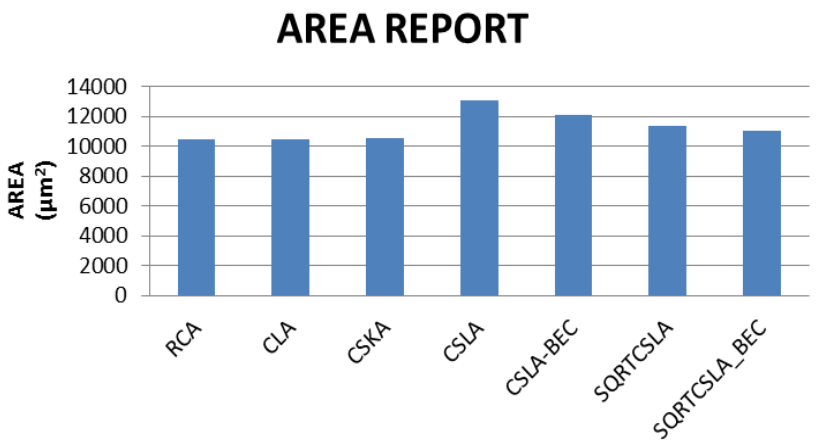

Fig. 25. Area report for all design corners

POWER REPORT

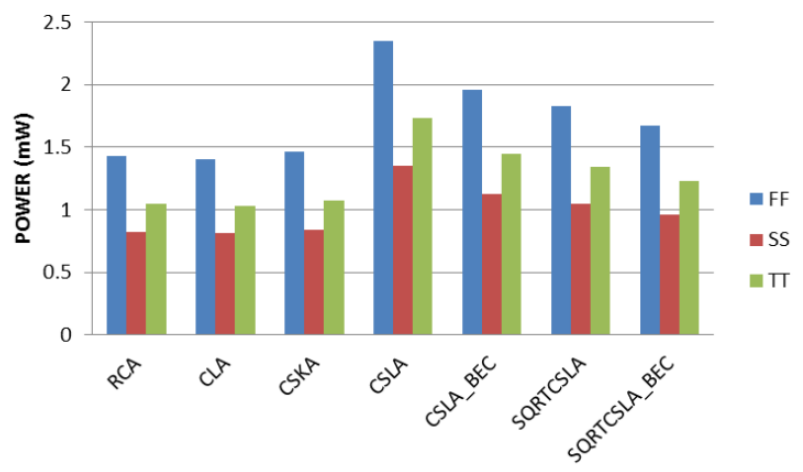

Fig. 26. Power report (Faradays $65 \mathrm{~nm}$ )

TIMING REPORT (FAST-FAST)

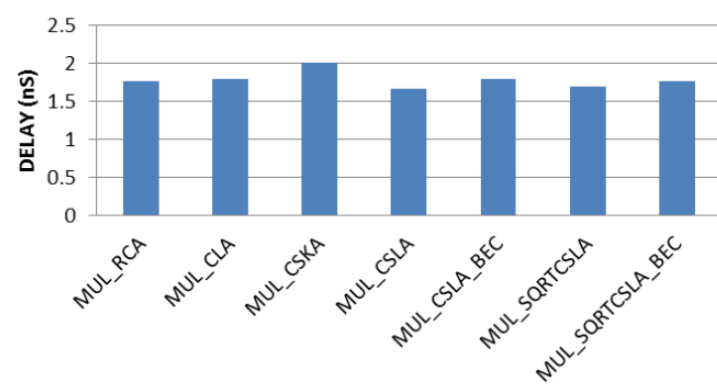

Fig. 27. Delay for Fast-Fast design corner (Faradays $65 \mathrm{~nm}$ )

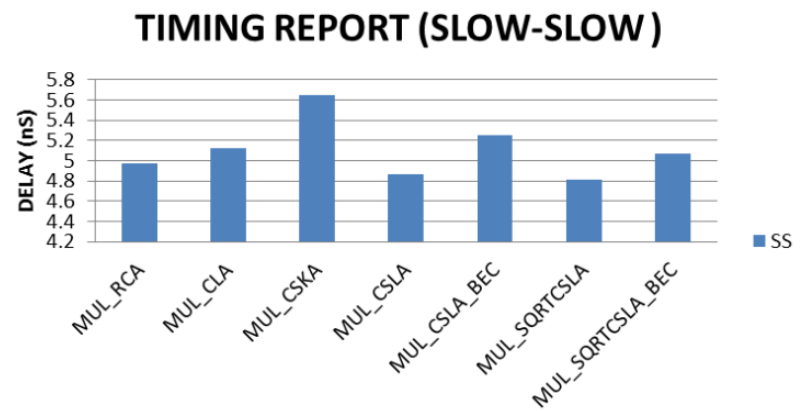

Fig. 28. Delay for Slow-Slow design corner (Faradays $65 \mathrm{~nm}$ )

\section{TIMING REPORT (TYPICAL-TYPICAL)}

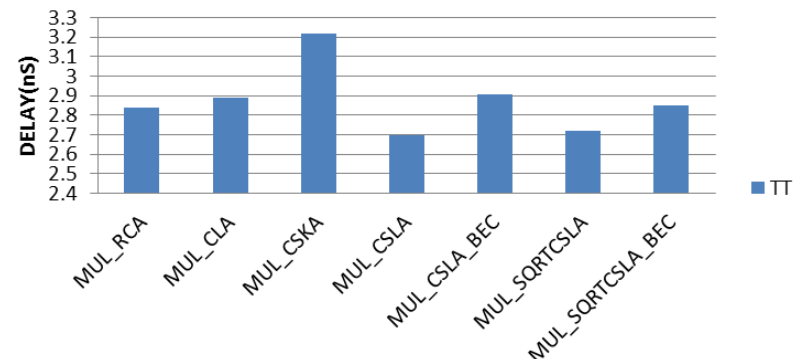

Fig. 29. Delay for Typical-Typical design corner (Faradays $65 \mathrm{~nm}$ )

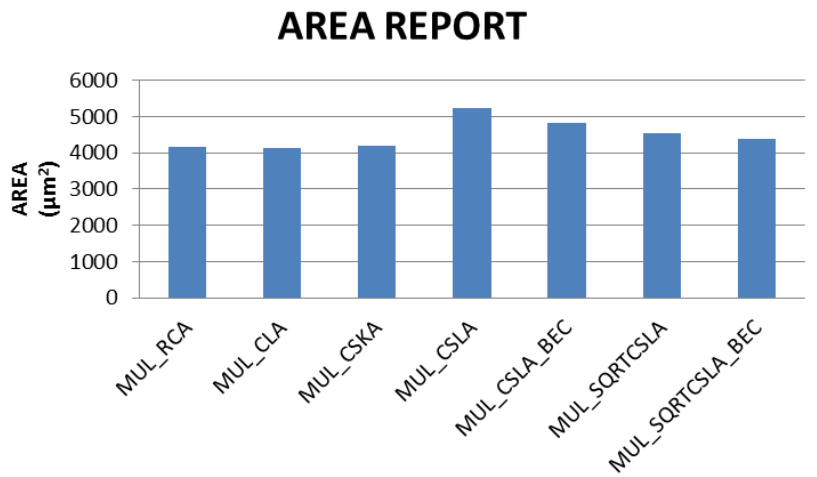

Fig. 30. Area Report (Faradays $65 \mathrm{~nm}$ )

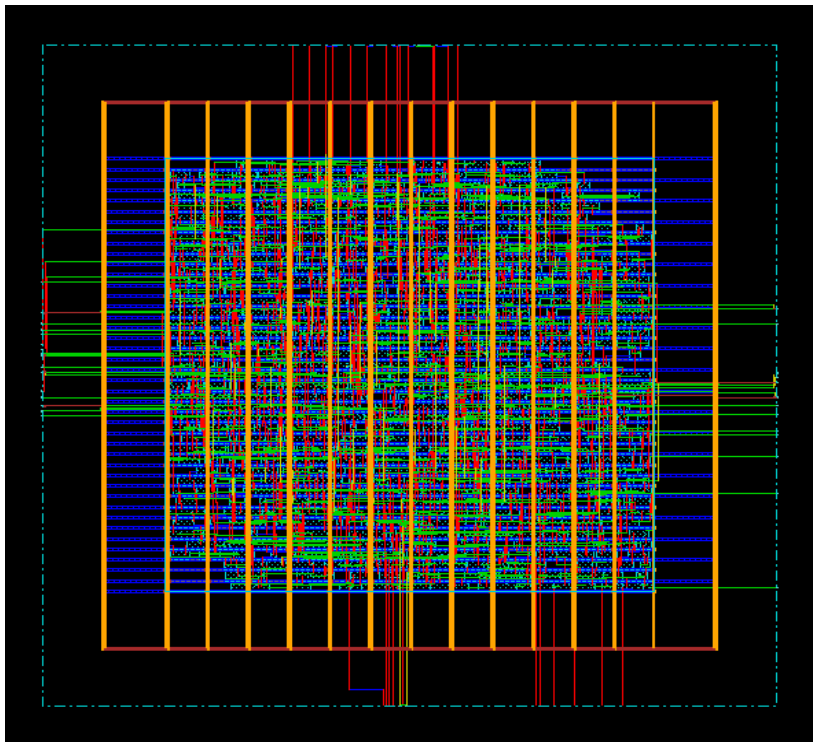

Fig. 31. Layout of Vedic multiplier using SQRT CSLA BEC (Faradays $180 \mathrm{~nm} \mathrm{FF}$ ) 


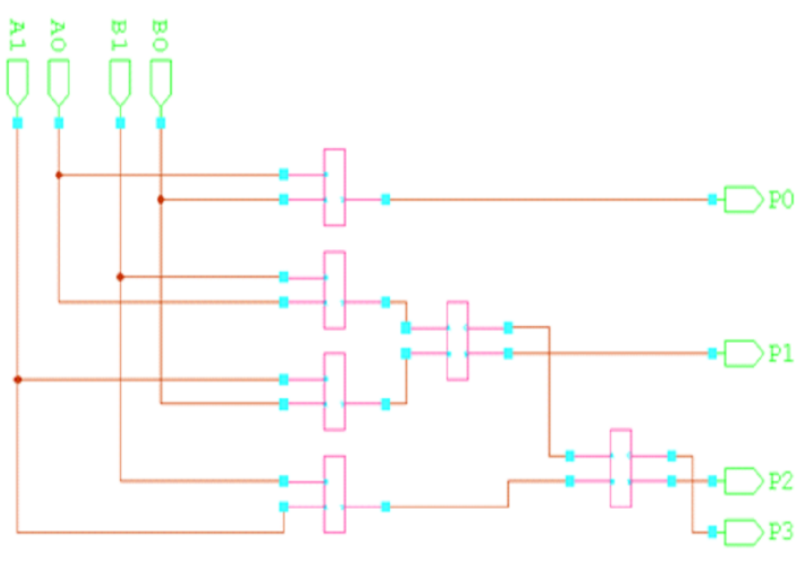

Fig. 32. Schematic of 2 bit Vedic multiplier

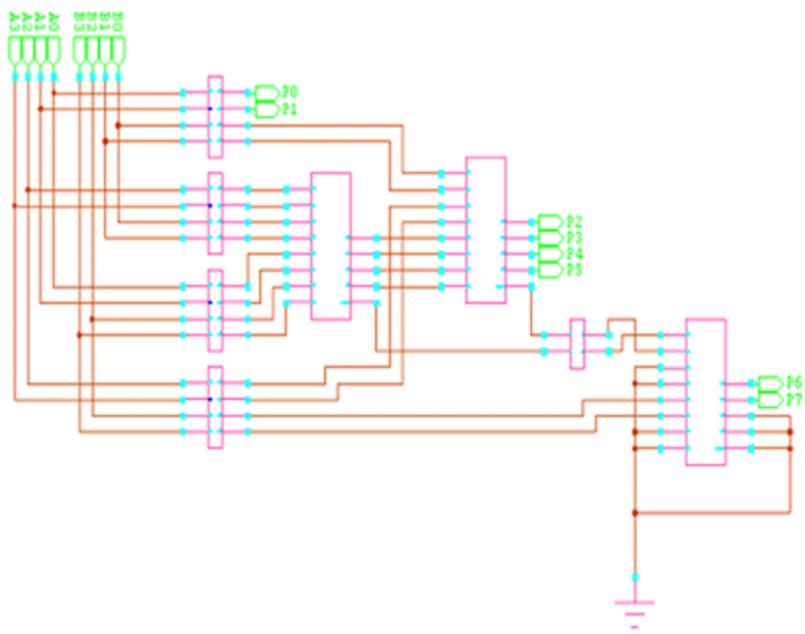

Fig. 33. Schematic of 4 bit Vedic multiplier

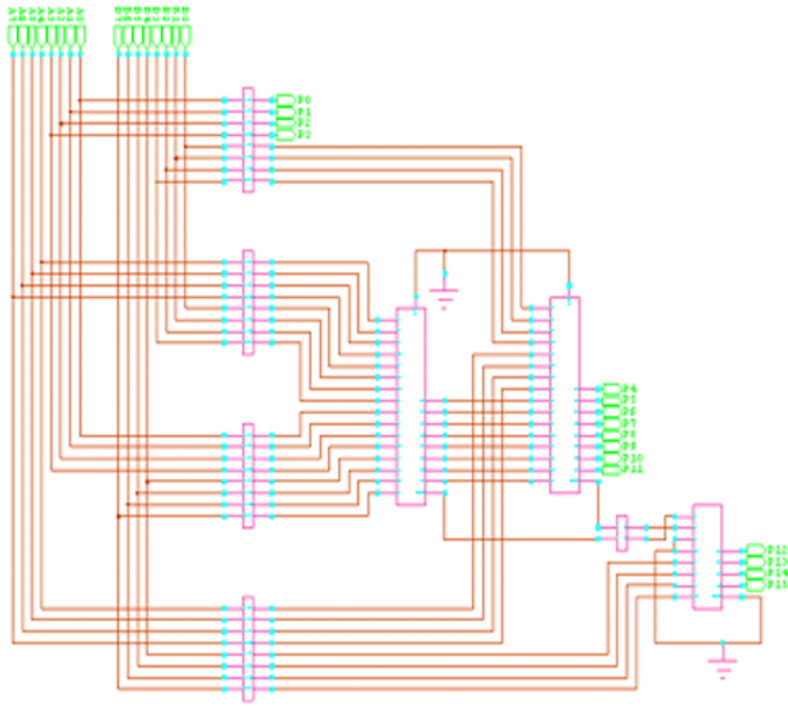

Fig. 34. Schematic of 8 bit Vedic multiplier

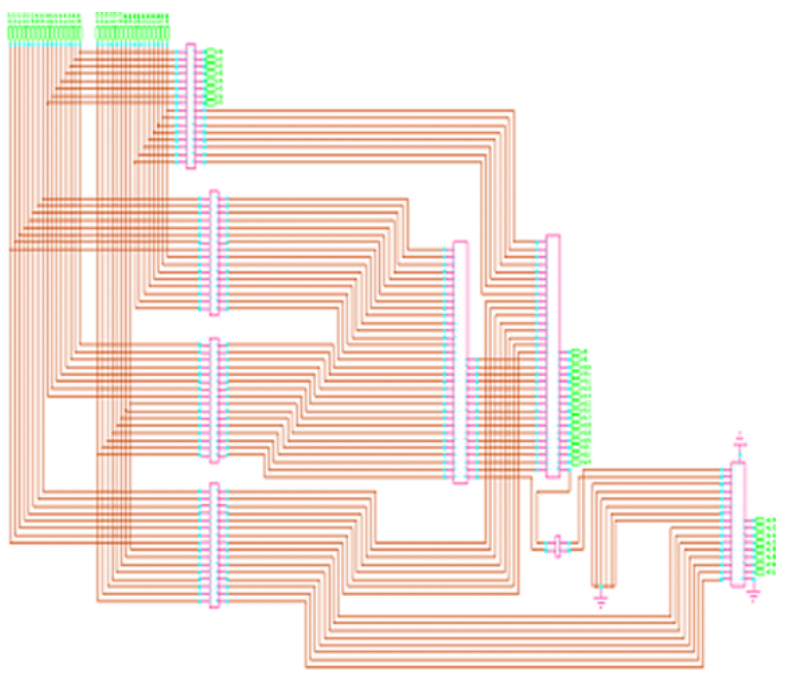

Fig. 35. Schematic of 16 bit Vedic Multiplier

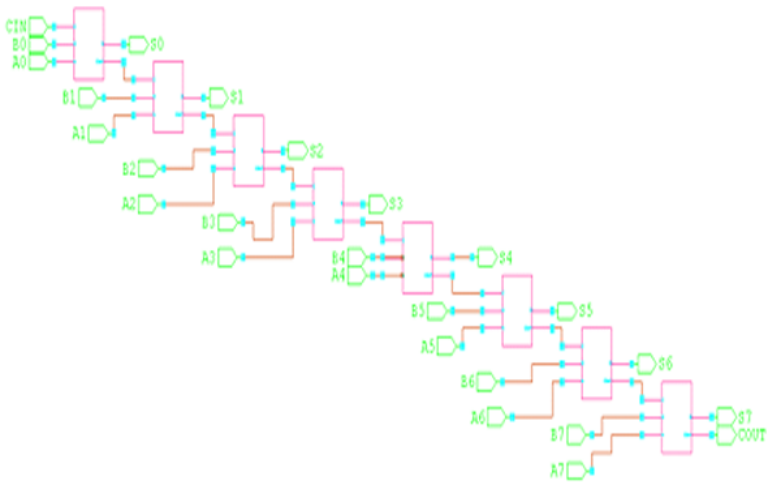

Fig. 36. Schematic of 8 bit Ripple Carry Adder

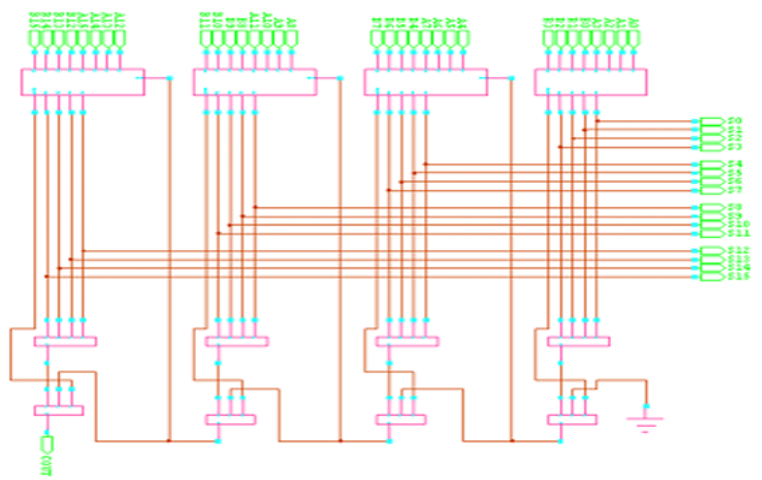

Fig. 37.Schematic of 16 bit Carry Skip adder

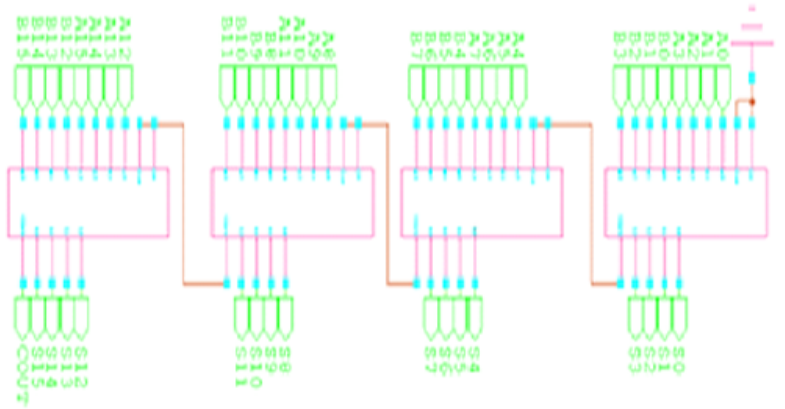




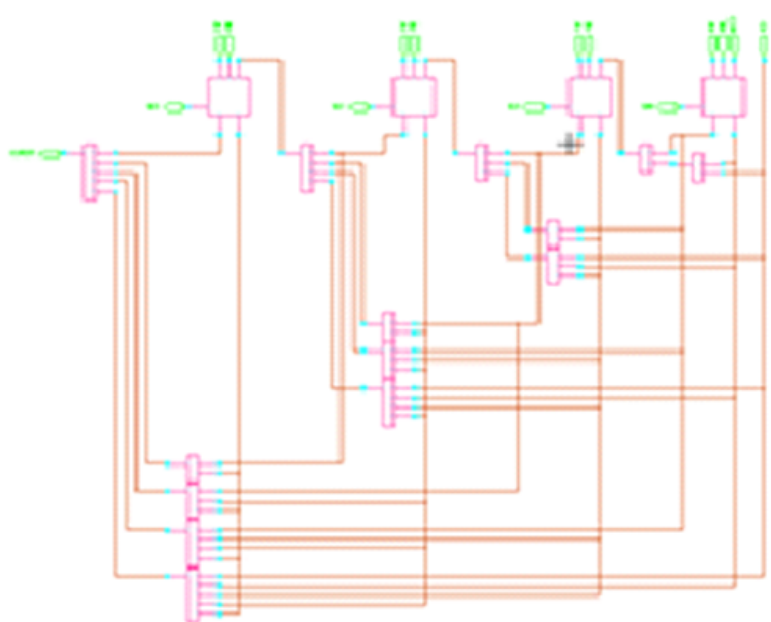

Fig. 38. Schematic of 16 bit Carry Look Ahead Adder

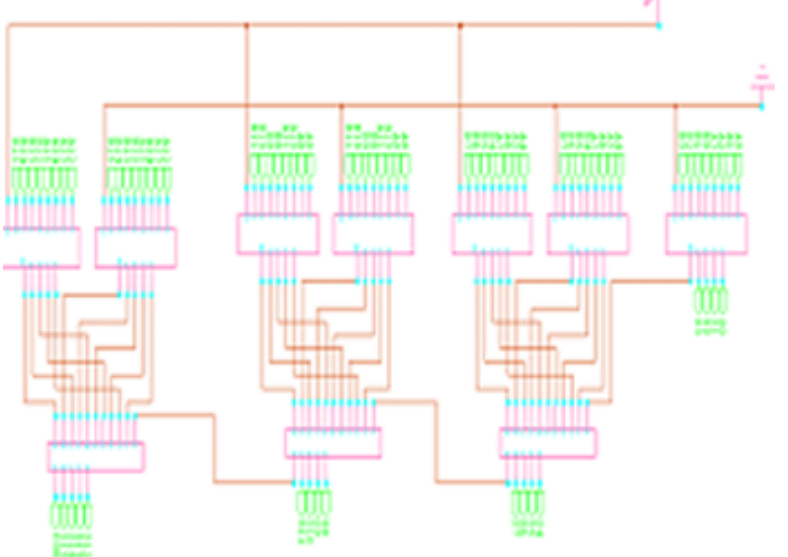

Fig. 39. Schematic of 16 bit Carry Select Adder

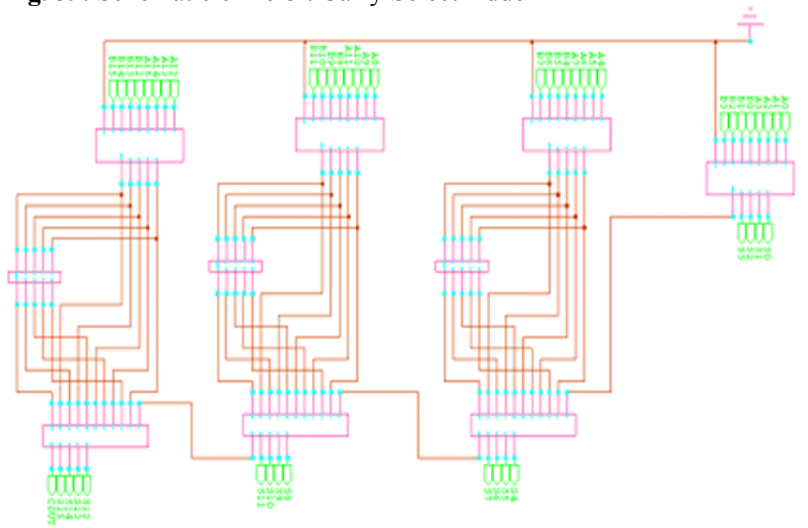

Fig. 40. Schematic of 16 bit Carry Select Adder using BEC

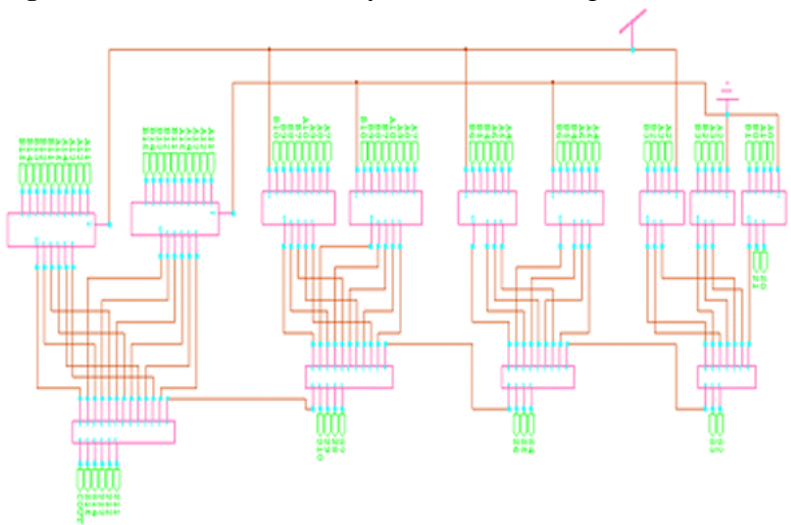

Fig. 41. Schematic of 16 bit Square root Carry Select adder

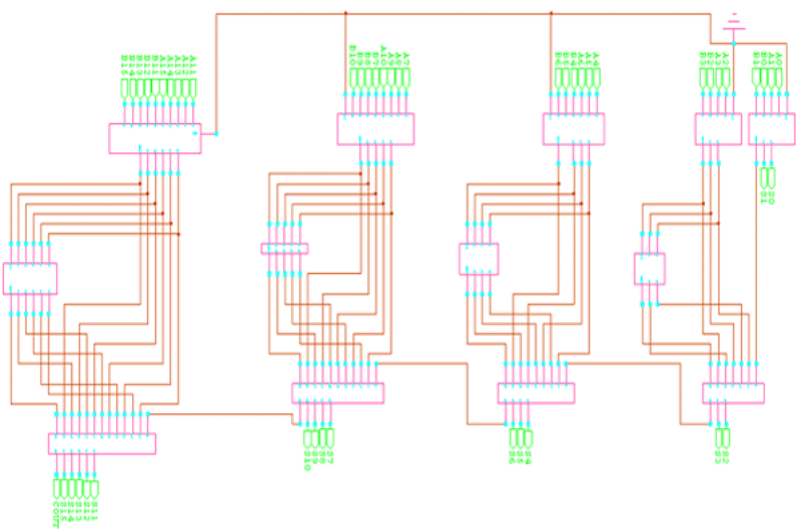

Fig. 42. Schematic of 16 bit Square root Carry Select Adder using BEC

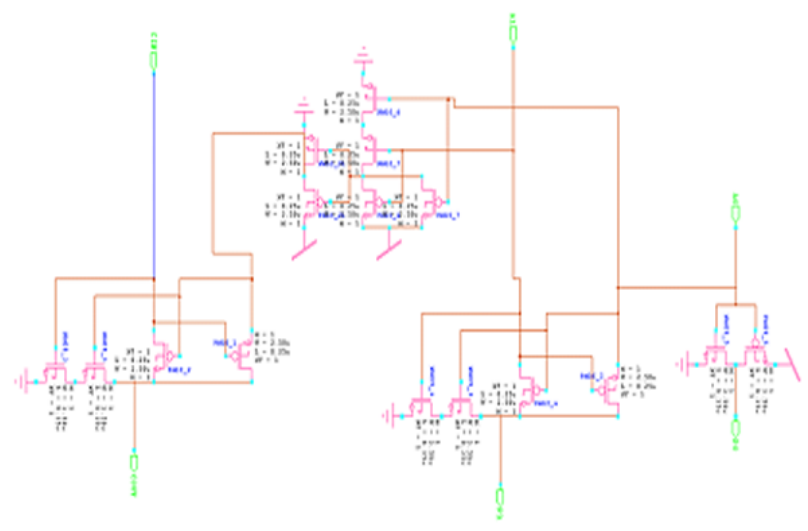

Fig. 43. Schematic of 3 bit BEC block

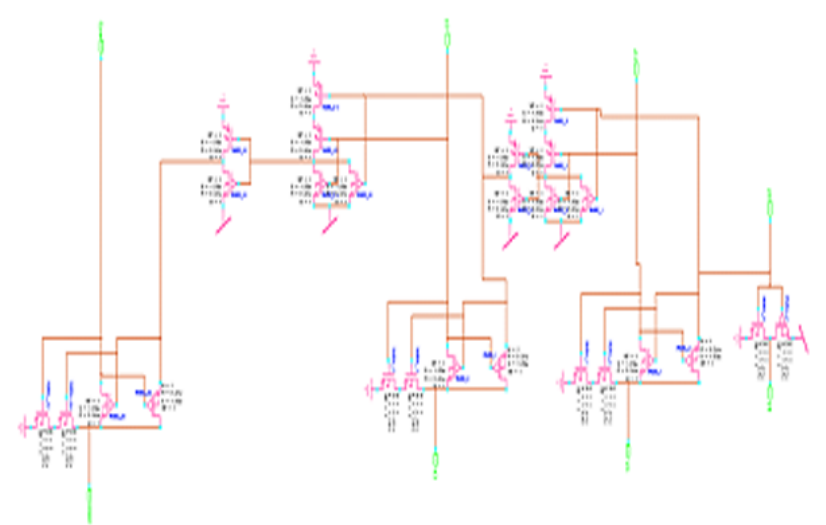

Fig. 44. Schematic of 4 bit BEC block

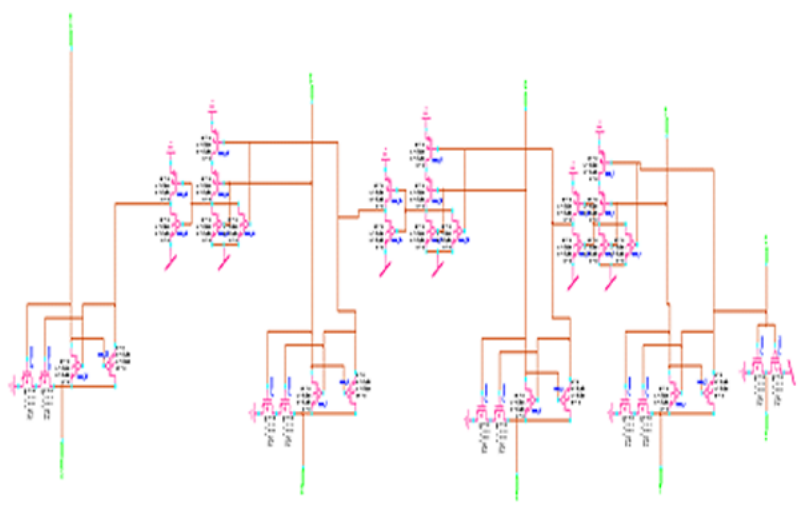

Fig. 45. Schematic of 5 bit BEC block 


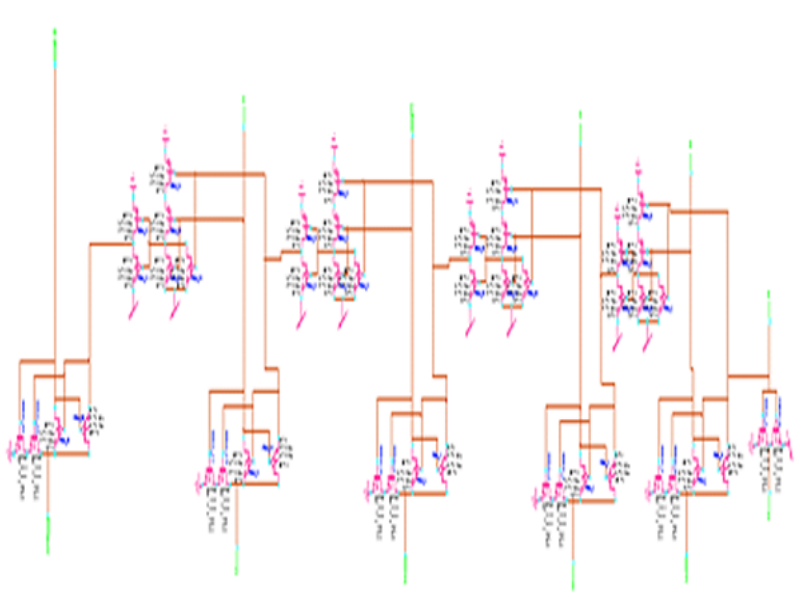

Fig. 46. Schematic of 6 bit BEC block

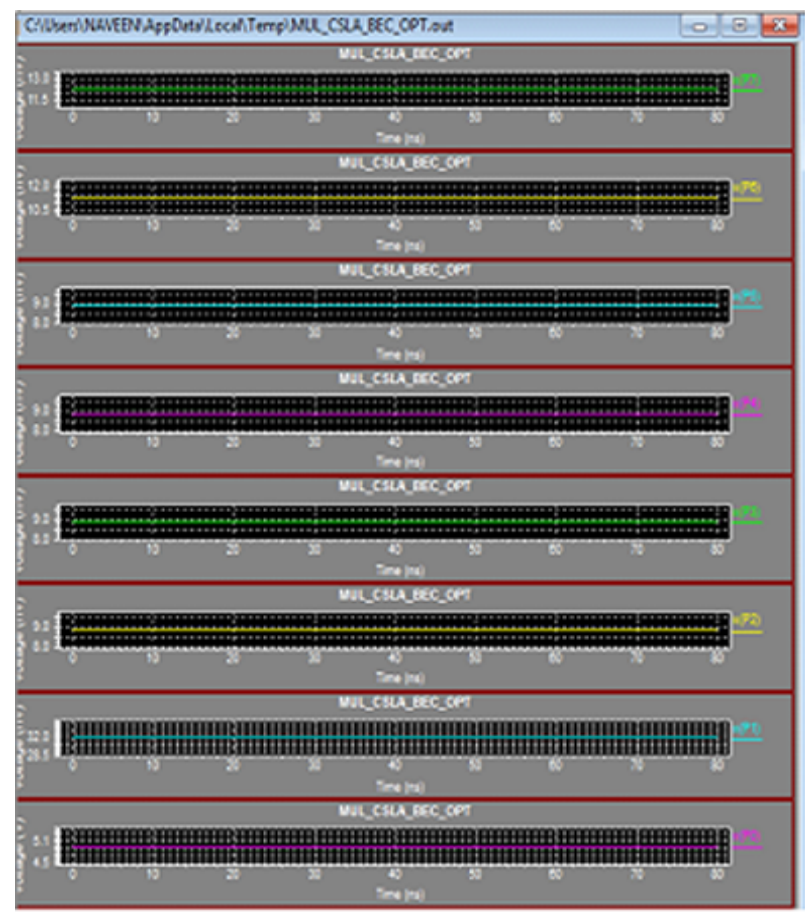

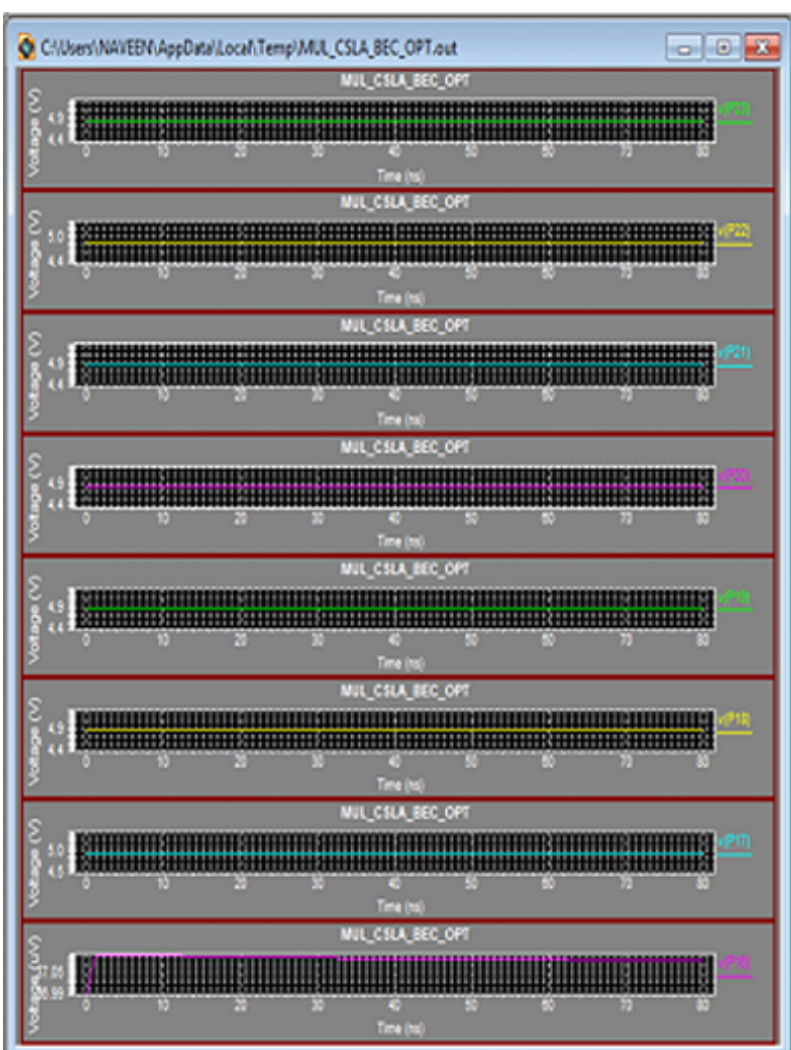

Fig. 47. Multiplier using Carry Select Adder with BEC outputs

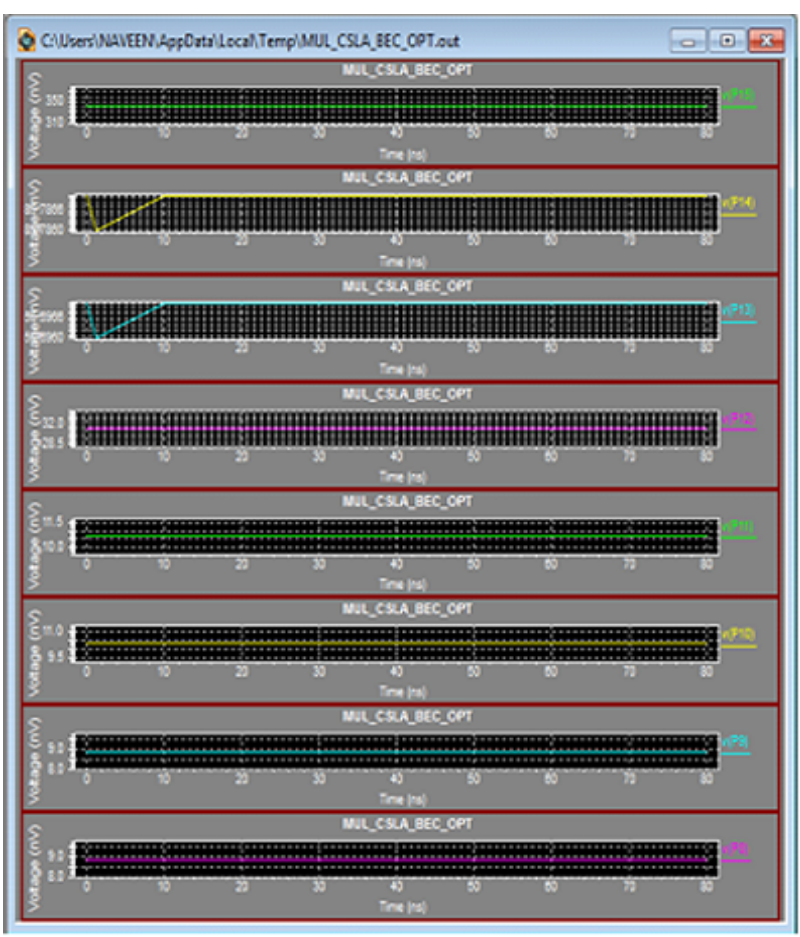




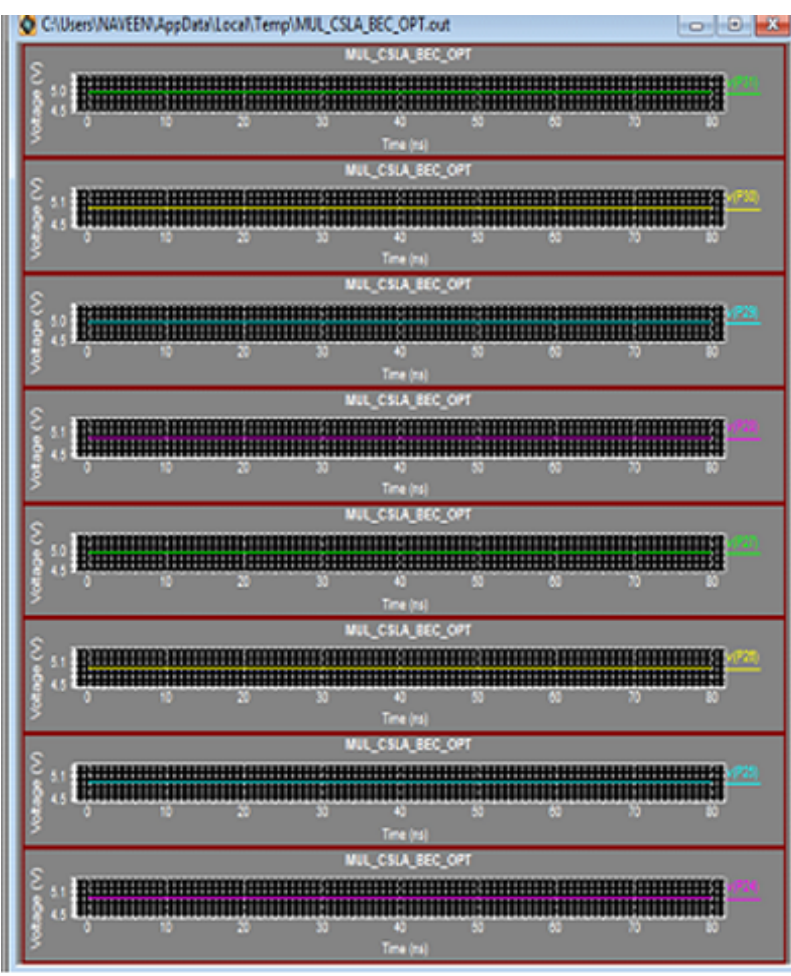

Table 7. Full Custom Results

\begin{tabular}{l|l|l}
\hline DESIGN & POWER(watts) & No.of gates \\
\hline MUL_RCA & $2.138968 \mathrm{e}^{\wedge}-002$ & 7692 \\
MUL_CSKA & $2.190428 \mathrm{e}^{\wedge}-002$ & 7852 \\
MUL_CSLA & $3.231109 \mathrm{e}^{\wedge}-002$ & 9396 \\
MUL_CSLA BEC & $3.020092 \mathrm{e}^{\wedge}-002$ & 7896 \\
MUL_SQRTCSLA & $2.935139 \mathrm{e}^{\wedge}-002$ & 8432 \\
MUL_SQRTCSLA & $2.882727 \mathrm{e}^{\wedge}-002$ & 8092 \\
BEC & & \\
\hline
\end{tabular}

The multiplier using ripple carry adder consumes least power because of the less hardware utilised in the architecture. The multiplier using carry select adder consumes the most power. The proposed multiplier using square root carry select adder consumes less power than the multiplier using carry select adder.

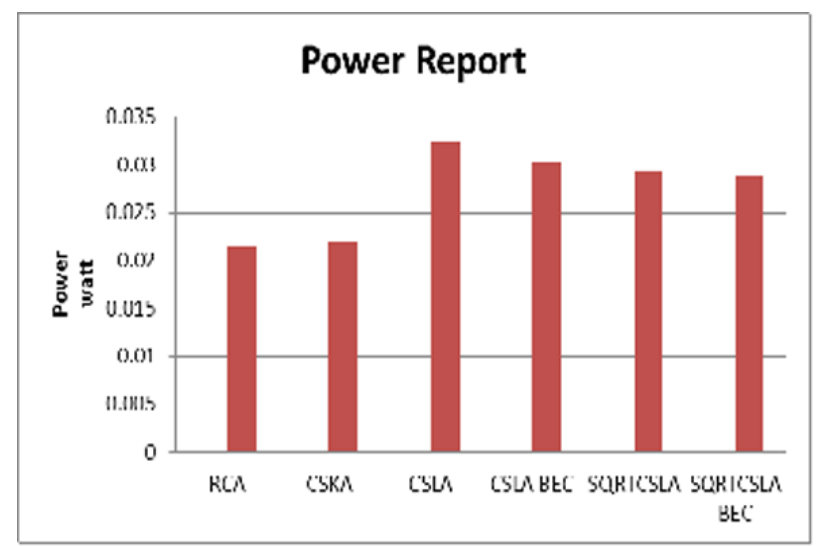

Fig. 48. Power Report

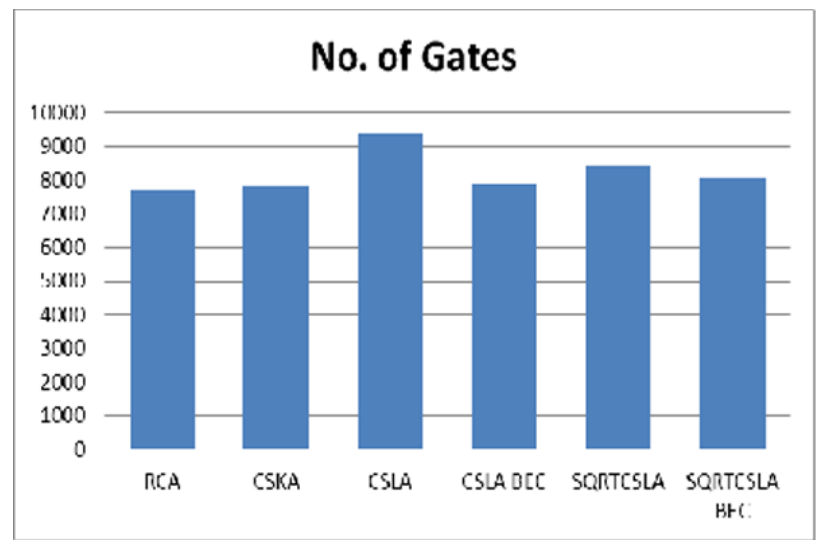

Fig. 49. No. of Gates

\section{Conclusion}

The vedic multiplier was designed using urdhavatiryakbhyam and implemented using semi-custom and full custom approaches. In the semi-custom approach the different proposed multipliers are realised in both Faraday's $180 \mathrm{~nm}$ technology as well as in $65 \mathrm{~nm}$ technology. The results of power, delay and area are analysed. From the result obtained from $180 \mathrm{~nm}$ technology, the multiplier carry select adder reduces the delay when compared to the multiplier using ripple carry adder it consumes more power. But in fast-fast design corner the multiplier using modified carry select adder using BEC consumes almost $1 \mathrm{~mW}$ power less than that of multiplier using carry select adder. The square root carry select adder is even better than these two designs consuming even less power and delay. The multiplier using square root carry select adder with BEC consumes only a slightly more power $(600 \mu \mathrm{W})$ than the ripple carry adder with a slight increase in delay. But, when the designs are implemented in $65 \mathrm{~nm}$ technology, the results are not very promising there is increase in both delay and power than the other designs. In the full custom design, the power alone is analysed. From the results, the multiplier using modified square root carry select adder with BEC consumes less power $(3.4 \mathrm{~mW})$ than the multiplier with carry select adder.

This is an Open Access article distributed under the terms of the Creative Commons Attribution Licence

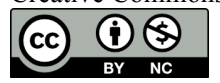

\section{References}

1. ShamimAkhter, "VHDL Implementation of fast NxN multiplier based on Vedic Mathematics," IEEE, ISBN: 978-1-4244-1341-6, ECCTD, 2007.
2. Kunchigi.V, "High Speed area efficient Vedic multiplier," IEEE, ISBN: 978-1-4577-1545-7,Mar. 2012. 
3. HimanshuThapliyal and M. B. Srinivas, "High speed efficient NxN bit parallel hierarchical overlay multiplier based architecture based on ancient Indian vedic mathematics," Transactions on Engineering computing and technology, vol. 2, Dec. 2004, ISSN 1305-5313.

4. Y. He, C. H. Chang, and J. Gu, "An area efficient 64-bit square root carry select adder for low power applications," in Proc. IEEE Int. Symp. Circuits Syst., 2005.
5. B. Ramkumar, H. M. Kittur, and P. M. Kannan, "ASIC Implementation of modified fast carry save adder," Eur. J. Sci. Res.,vol.2, 2010.

6. T. Y. Ceiang, and M. J. Hsiao, "Carry select adder using single ripple carry adder," Electron. Lett., 1998.

7. O. J. Bedriji, "Carry select adder," IRE Trans. Electron. Comput., pp. 340-344. 